Review

\title{
Self-Assembly of Block and Graft Copolymers in Organic Solvents: An Overview of Recent Advances
}

\author{
Leonard Ionut Atanase ${ }^{1,2, *}$ (10) and Gerard Riess ${ }^{3}$ \\ 1 Faculty of Dental Medicine, “Apollonia” University, 700399 Iasi, Romania \\ 2 Research Institute "Academician Ioan Haulica", 700399 Iasi, Romania \\ 3 University of Haute Alsace, Ecole Nationale Supérieure de Chimie de Mulhouse, \\ Laboratoire de Photochimie et d'Ingénierie Macromoléculaires, 68093 Mulhouse CEDEX, France; \\ gerard.riess@uha.fr \\ * Correspondence: leonard.atanase@yahoo.com; Tel.: +40-741-686-687
}

Received: 20 November 2017; Accepted: 6 January 2018; Published: 11 January 2018

\begin{abstract}
This review is an attempt to update the recent advances in the self-assembly of amphiphilic block and graft copolymers. Their micellization behavior is highlighted for linear AB, $\mathrm{ABC}$ triblock terpolymers, and graft structures in non-aqueous selective polar and non-polar solvents, including solvent mixtures and ionic liquids. The micellar characteristics, such as particle size, aggregation number, and morphology, are examined as a function of the copolymers' architecture and molecular characteristics.
\end{abstract}

Keywords: self-assembly; micelle; organic solvents; block copolymers; graft copolymers; triblock terpolymers

\section{Introduction}

The self-assembly and micellization of block and graft copolymers with the formation of structured nanoparticles have attracted a major interest over the last decades. Since the pioneering studies of Tuzar and Kratochvil [1] on micellar systems in organic solvents, one of the major research trends afterward was to develop aqueous-based systems. These systems are of considerable interest in biomedical applications. This field has been quite extensively reviewed by different research groups [2-6]. During the same time period, the research activity on non-aqueous micellar systems was ongoing, but somehow to a minor extent, as outlined by the review articles published at the beginning of this century [7-9].

Therefore, the aim of the present review article is to update and highlight the recent advances related to the self-assembly of block and graft copolymers in non-aqueous media. This topic is one of interest not only from a theoretical point of view, but also due to its widespread application possibilities in membrane technology, surface modification of pigments and fillers, non-aqueous dispersion, lubricant additives, etc. In addition to these specific applications, non-aqueous micellar systems may have certain advantages with respect to the aqueous micellar dispersions. In fact, it has to be recalled that the micelle's characteristics generated by a polyA-b-polyB copolymer in the presence of selective aqueous or organic solvent $S$ are depending to a large extent to the Flory-Huggins interaction parameter, such as $\chi_{\mathrm{AB}}, \chi_{\mathrm{AS}}$ and $\chi_{\mathrm{BS}}$, which are the polymer/polymer and the polymer/solvent interaction parameters, respectively. These parameters are furthermore directly correlated with the solubility parameter $\delta$ of the compounds. In the common practice, with a homologues series of organic solvents, such as alcanes, esters, or alcohols, it will therefore be easier than for pure water to adjust the $\chi$ values of the solvent to $\chi$ values of the copolymer sequences. Finally, it is quite obvious that the self-assembly of hydrophobic/hydrophobic copolymers, which correspond to a large part of those synthesized up to now, may be achieved only in organic media. 
In view of this background, the present literature survey from the last decade, including the authors' contributions, is structured as follows: (i) a brief section is provided in order to review the experimental techniques; (ii) the self-assembly of linear $A B$ and ABA block copolymers in polar and non-polar solvents, as well as in specific solvent mixtures and in ionic liquids (ILs), are outlined; (iii) a major section is then devoted to $A B C$ linear triblock terpolymers and their specific multi-compartment micellar morphologies; and, (iiii) the micellization aspects of graft copolymers and their possibility of forming unimolecular micelles will be described in the last section.

Out of scope of this review are the following topics: bottle-brush micelles; rod-coil copolymers; interpolymer complexes of block and graft copolymers; and, micellization in super critical carbon dioxide $\left(\mathrm{CO}_{2}\right)$.

\section{Experimental Section}

\subsection{Synthesis and Molecular Characteristics}

It is now accepted that well-defined block and graft copolymers can be obtained by living sequential and controlled radical polymerization techniques [10-16]. However, one has to bear in mind that even the so-called well-defined copolymers may present a non-negligible polydispersity in their composition and molecular weight for linear $\mathrm{AB}, \mathrm{ABA}$, and $\mathrm{ABC}$ block copolymers. The same type of limitation not only affects block copolymers, but graft copolymers as well. In addition, a polydispersity in graft density has to be considered for graft copolymers.

From a practical point of view, it is worth noting that $A B$ block copolymers can also be synthesized by the so-called Polymerization Induced Self-Association (PISA) technique, which is carried out essentially in organic solvents. In-situ micellization is directly involved in this synthesis technique, as outlined recently by Armes and coworkers [17-21]. The determination of the copolymers' molecular characteristics, such as molecular weight, composition, and end-group functionality, is well-documented in recent review articles [10-12].

\subsection{Solvents}

It is well-established that the solubility of a given polymer is directly defined by the Flory-Huggins solvent/polymer interaction parameter $(\chi)$. However, this parameter is not always available. Therefore, for the selection of a selective solvent, which is required in order to induce the self-assembly of a block or graft copolymer, it is of common practice to use the concept of "solubility parameter" $(\delta)$ of solvents and polymers. Among the various solubility scales, the Hildebrand $\delta$ value is the most frequently used. The $\delta_{t}$ value involves the dispersive $\delta_{d}$ and polar $\delta_{p}$, as well as the hydrogen bonding $\delta_{\mathrm{h}}$ contributions, such as: $\delta_{\mathrm{t}}=\left(\delta_{\mathrm{d}}^{2}+\delta_{\mathrm{p}}{ }^{2}+\delta_{\mathrm{h}}{ }^{2}\right)^{1 / 2}$. For non-ionic solvents, and particularly for aliphatic hydrocarbon compounds, $\delta_{\mathrm{p}}$ and $\delta_{\mathrm{h}}$ are negligible with respect to $\delta_{\mathrm{d}}$. The $\delta_{\mathrm{t}}$ values are therefore in the range of 15 to $18 \mathrm{MPa}^{1 / 2}$. This approach is advantageous for solvent mixtures, often used in micellization studies, because defining an "average solubility parameter" is possible. The usual non-aqueous solvents used in the micellization experiments are listed in Table 1, with an indication of their solubility parameter [22].

Table 1. Solubility parameters $(\delta)$ of the most usual non-polar and polar solvents.

\begin{tabular}{cccc}
\hline Non-Polar Solvents & $\boldsymbol{\delta}\left(\mathbf{M P a}^{\mathbf{1 / 2}}\right)$ & Polar Solvents & $\boldsymbol{\delta} \mathbf{( \mathbf { M P a } ^ { \mathbf { 1 } } \mathbf { ) }}$ \\
\hline$n$-Hexane & 14.9 & Ethyl acetate & 18.1 \\
$n$-Heptane & 15.2 & Dichloromethane & 19.8 \\
$n$-Decane & 15.8 & Acetone & 19.9 \\
Hexadecane & 16.3 & THF & $19.5-20.2$ \\
Cyclohexane & 16.7 & Isopropanol & 23.6 \\
Toluene & 18.2 & n-Propanol & 24.4 \\
\hline
\end{tabular}


Table 1. Cont.

\begin{tabular}{cccc}
\hline Non-Polar Solvents & $\boldsymbol{\delta}\left(\mathbf{M P a}^{\mathbf{1 / 2}}\right)$ & Polar Solvents & $\boldsymbol{\delta} \mathbf{( \mathbf { M P a } ^ { \mathbf { 1 / 2 } } )}$ \\
\hline Chloroform & 18.7 & Acetonitrile & 24.4 \\
1,4-Dioxane & $19.9-20.5$ & DMF & 24.9 \\
& & DMSO & 26.5 \\
& & Ethanol & 26.5 \\
& & Methanol & 29.7 \\
& & Water & 47.9 \\
& & Ionic liquids & $24.0-32.0$ \\
\hline
\end{tabular}

\subsection{Self-Assembly Techniques}

The self-assembly techniques and the micellar characterization methods used for amphiphilic block and graft copolymers have been described in several review articles [7-9,23]. The simplest method for the preparation of micelles is the direct dissolution of copolymer samples in a selective solvent for one of the sequences. It has to be kept in mind that this procedure is recommended only for copolymers with low molecular weights and short insoluble sequences. In another technique, the micellization occurs by the addition of a non-solvent to a common solvent, in which the copolymer is initially molecularly dispersed. However, this technique may induce aggregate formation. In order to avoid the formation of agglomerates, the dialysis technique, starting from a common solvent, is the recommended method for the micelle preparation. Notably, the nano-rings, an elaborate morphology, became available by surface induced self-assembly, by forming a thin film on specific surfaces, such as mica and silicone wafers. This procedure occurs through the solvent evaporation of the copolymer solution on the surface, which induces a "frozen-in" structure that is maintained after re-dissolution of the thin film [24]. From these studies, it turns out that, for a given copolymer sample, the self-association procedure has a major influence on its micellar characteristics, such as morphology, size, and size distribution.

It has to be noticed that some of these techniques may lead to kinetically "frozen-in" situations instead of a thermodynamic equilibrium between unimers and micelles, which are usually only observed when the core-forming polymer sequence has a low glass transition temperature $\left(T_{\mathrm{g}}\right)$. As a general remark, it appears from the present literature survey that a strict distinction is not always made between kinetic "frozen-in" self-assembled systems and micelles in thermodynamic equilibrium with their unimers.

Finally, by the "crystallization-driven self-assembly" (CDSA) method, intensively studied by the groups of Winnik and Manners for poly(ferrocenylsilanes)-based copolymers, especially cylindrical micelles can be obtained from crystallizable block copolymers having a crystalline core block that is much smaller than the corona sequence [25-27].

\subsection{Characterization Techniques}

The critical micellar concentration (CMC), as well as the critical micellization temperature (CMT), are fundamental characteristics of copolymers solutions in a unimer/micelle thermodynamic equilibrium. CMC values are usually accessible by different fluorescence techniques [28,29], and to a minor extent, by surface tension measurements. Moreover, it has to be noted that the CMC values determined for "frozen-in" systems might be questionable. The micellar hydrodynamic diameter, $D_{\mathrm{h}}$, is determined by dynamic light scattering (DLS), transmission electron microscopy (TEM), and SAXS [30]. The micellar morphologies can be observed with different electron microscopy techniques, such as TEM and scanning electron microscopy (SEM). In particular, cryo-TEM and tomography has been applied by different authors [31-33] for the direct visualization of micellar nano-structures. In addition to these well-described size and morphology characterization techniques, other elaborate methods are available for the study of block copolymers self-assembly in organic 
media, such as super-resolution fluorescence microscopy technique, which is especially used for the visualization of cylindrical micelles obtained from crystallizable copolymers by the CDSA method [34].

\section{AB and ABA Linear Block Copolymers in Organic Solvents}

Within this overview of block copolymer self-assembly in organic solvents, the logical approach was to first consider the simplest molecular architectures of $\mathrm{AB}$ and $\mathrm{ABA}$ copolymers. This section provides a review of the micellar characteristics during the self-assembly of $A B$ and $A B A$ copolymers in non-polar and polar solvents, including their mixtures and ionic liquids (ILs), as well as in biocompatible solvents. This self-assembly is further described for $\mathrm{AB}$ copolymers, including crystallizable sequences.

The basic micellar morphologies correspond to spheres, cylinders, and vesicles, depending on the molecular characteristics of the copolymers, the selective solvent, and the micellization conditions. Figure 1 is an illustration of these basic morphologies.

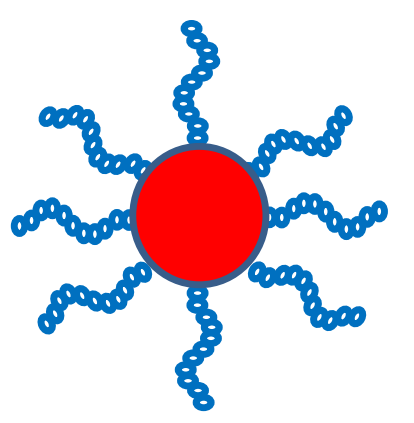

Spherical micelle

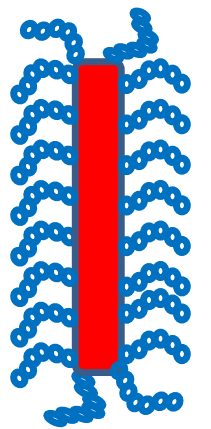

Rod-like micelle

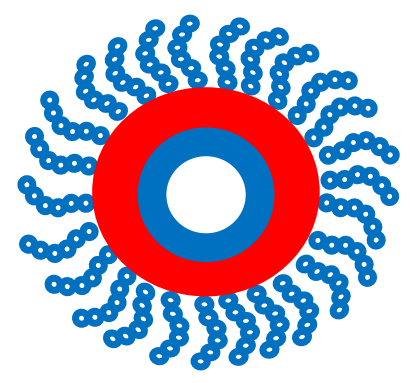

Vesicle

Figure 1. Basic micellar morphologies for AB copolymers.

It has to be recalled that a given amphiphilic $A B$ copolymer in a selective solvent of either the $A$ or $B$ block leads to two types of morphologies having either an A or B micellar core, respectively. This micellar structure inversion can also be created by thermal treatment, as demonstrated by $\mathrm{Li}$ et al. [35] for the self-assembly of poly(tert-butylmethacrylate)- $b$-poly[ $N$-(4-vinylbenzyl)- $N, N$-diethylamine] (PtBMA- $b$-PVEA) copolymers in methanol. This possibility is schematically outlined in Figure 2:

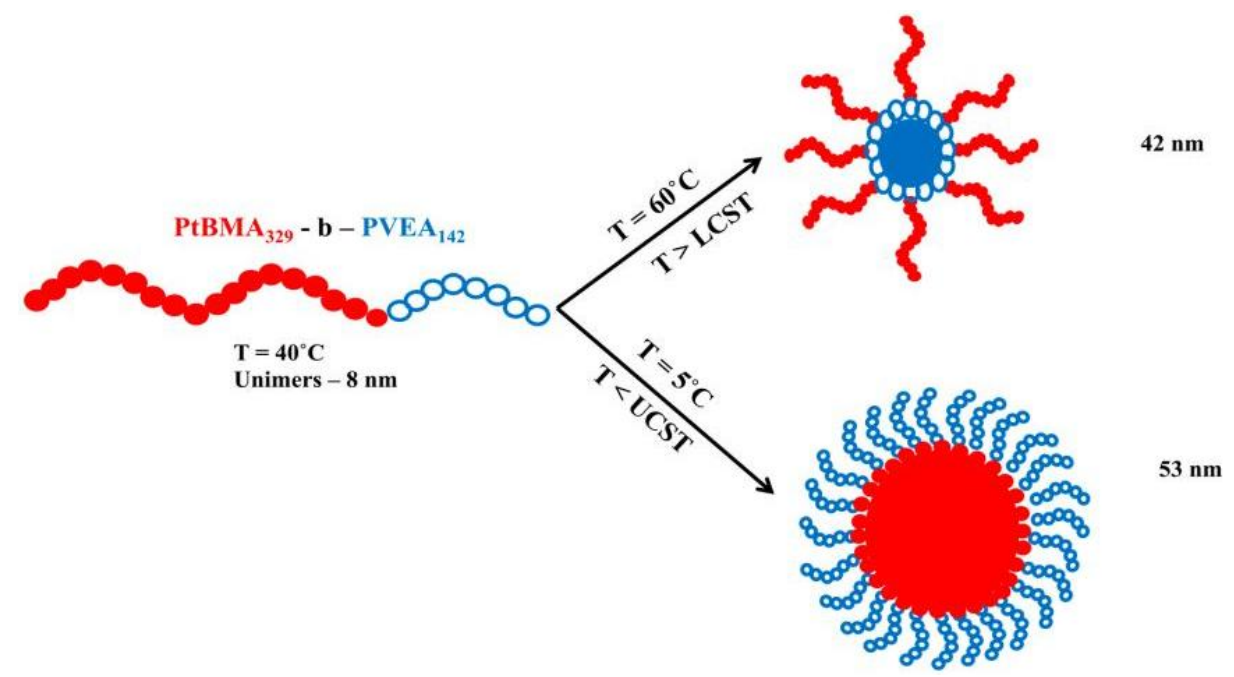

Figure 2. Micellization characteristics of $\mathrm{PtBMA}_{329}-b-\mathrm{PVEA}_{142}$ copolymer in methanol as a function of temperature (lower critical solution temperature (LCST) $=53^{\circ} \mathrm{C}$; upper critical solution temperature $\left.(\mathrm{UCST})=32^{\circ} \mathrm{C}\right)$. Adapted from Li et al. [35]. 


\subsection{Self-Assembly of $A B$ and ABA Block Copolymers in Non-Polar Selective Solvents}

Micellization of well-defined AB block copolymers, such as poly(butadiene)-b-poly(styrene) (PB- $b$-PS) and poly(isoprene)- $b$-poly(styrene) (PI-b-PS), has been studied quite extensively in the second half of the 20th century [1,7,36-39]. From the relatively few papers published on this topic since then, the objectives of the authors were mainly to examine specific aspects of the self-assembly of $\mathrm{AB}$ diblock copolymers in non-aqueous media. An interesting example of this type of study was that of Sotiriou et al. [37]. For a series of PS-b-PI diblock copolymers, tagged with a $w$-lithium sulfonate $\left(\mathrm{SO}_{3} \mathrm{Li}\right)$ end group on either the PS or PI sequence, these authors examined the micellization behavior in $n$-decane as a function of the localization of the polar end-group. A micellar solution was obtained by direct dissolution and heating the block copolymer samples in $n$-decane. The principal micellar characteristics of these systems at $25^{\circ} \mathrm{C}$ are provided in Table 2 .

Table 2. Micellar characteristics for the PS- $b$-PI diblock copolymers in $n$-decane at $25^{\circ} \mathrm{C}$ as determined by Sotiriou et al. [37].

\begin{tabular}{ccc}
\hline Sample & Nagg & Rh (nm) \\
\hline $\mathrm{PS}_{60}-b-\mathrm{PI}_{203}$ & 10.2 & 10.4 \\
\hline$\left(\mathrm{SO}_{3} \mathrm{Li}\right)-\mathrm{PS}_{60}-b-\mathrm{PI}_{203}$ & 23.4 & 14.2 \\
\hline $\mathrm{PS}_{55}-b-\mathrm{PI}_{151}-\left(\mathrm{SO}_{3} \mathrm{Li}\right)$ & 17.0 & $660.0^{\mathrm{a}}$ \\
\hline & $11.0^{\mathrm{b}}$ & $75.0^{\mathrm{b}}$ \\
\hline
\end{tabular}

${ }^{\mathrm{a}}$ large polydispersity. ${ }^{\mathrm{b}}$ values at $30^{\circ} \mathrm{C}$.

These results prove that the position of the $\mathrm{SO}_{3} \mathrm{Li}$ end-group has a considerable influence on the micellar characteristics. The $\mathrm{SO}_{3} \mathrm{Li}$ end-group fixed on the PS sequence, which forms the micellar core, leads to an increase in both $N_{\text {agg }}$ and $R_{\mathrm{h}}$, with respect to the unlabeled sample. This effect may be attributed to the dipolar interaction of the $\mathrm{SO}_{3} \mathrm{Li}$ groups in a non-aqueous medium. For the $\mathrm{SO}_{3} \mathrm{Li}$ end-groups on the PI sequence, this interaction occurs in the solvent phase between the micelles as a result of the formation of polydisperse and interconnected $\mathrm{SO}_{3} \mathrm{Li}$ large aggregates with the PS cores.

Later on, Cheng et al. [40] studied the morphological changes of non-functionalized PS- $b$-PI copolymer in $n$-decane as a function of temperature and pressure using small-angle neutron spectroscopy (SANS). According to the authors, the increase in pressure from 200 to 16,000 psi, at room temperature, had no effect on the micellar characteristics $\left(N_{\mathrm{agg}}, R_{\mathrm{g}}\right.$, and $\left.R_{\text {core }}\right)$, but led to the formation of micellar agglomerates. At $60^{\circ} \mathrm{C}$ and high pressure, the micelles underwent a macro-phase separation with the formation of sheet-like aggregates. The authors indicated that these morphological changes are attributed to the decrease of the " $n$-decane quality" for the PI sequences.

Growney et al. [41] examined the self-assembly of poly(styrene)-b-poly(ethylene propylene) (PS- $b$-PEP) diblock copolymers that are obtained by the hydrogenation of the PI sequence of PS- $b$-PI copolymers. As selective non-polar solvents of PEP, either $n$-heptane $\left(\delta=15.2 \mathrm{MPa}^{1 / 2}\right)$ or $n$-dodecane $\left(\delta=16.0 \mathrm{MPa}^{1 / 2}\right)$ was used, and star-like micelles with an $R_{\mathrm{h}}$ of around $40 \mathrm{~nm}$ were obtained in both of the solvents. The self-association of another type of PI-based diblock copolymer, such as poly(ethylene oxide)-b-poly(isoprene) (PEO- $b$-PI), was investigated by Bartels et al. [42] in $n$-decane. In this case, the micellar solutions were obtained using a precipitation method starting from a homogeneous copolymer solution in tetrahydrofuran (THF).

Wang et al. [43] observed by DLS a bimodal distribution attributed to unimers and spherical micelles for the self-assembly of a series of poly(styrene)-b-poly(2-vinyl pyridine) (PS- $b$-P2VP) diblock copolymers in the presence of a pure non-polar solvent, such as toluene. Moreover, these authors investigated the micellar aggregate formation by mixing different architectures of this type of copolymers, such as linear diblocks and triblocks, as well as branched star-like copolymers.

Finally, Arai et al. [44] studiedthe self-aggregation behavior of PS-based diblock copolymers in chloroform and 1,2-dichloroethane (DCE), using DLS and SLS. The micellar characteristics a series of 
poly(styrene)- $b$-poly[(ar-vinylbenzyl)trimethylammonium chloride] (PS- $b$-PV) diblock copolymers, obtained by RAFT polymerization, were directly correlated with the number average polymerization degree $\left(D P_{\mathrm{n}}\right)$ ratio of the two blocks. For example, star-like micelles were observed for a ratio $D P_{\mathrm{n}}(\mathrm{PS}) / D P_{\mathrm{n}}(\mathrm{PV})>6$, whereas brush-like micelles were obtained if this ratio was smaller than 6 .

\subsection{Self-Assembly of $A B$ and $A B A$ Block Copolymers in Polar Selective Solvents}

In this section, the recent micellization studies completed for $\mathrm{AB}$ and $\mathrm{ABA}$ block copolymers in different pure polar solvents are summarized (Table 3).

Table 3. Micellization studies of AB block copolymers in pure polar solvents.

\begin{tabular}{|c|c|c|c|c|}
\hline AB Block Copolymers & $\begin{array}{l}\text { Selective Solvent } \\
\text { for A Block }\end{array}$ & $\begin{array}{c}\text { Selective Solvent } \\
\text { for B Block }\end{array}$ & Micellar Characteristics & Ref. \\
\hline $\mathrm{PS}_{48}-b-\mathrm{PNVP}_{99}$ & - & $\mathrm{CH}_{3}-\mathrm{OH}$ & $\begin{array}{c}R_{\mathrm{h}}=16 \mathrm{~nm} \\
R_{\mathrm{g}} / R_{\mathrm{h}}=0.65 \\
\text { C.M.C. }=0.13 \mathrm{mg} \cdot \mathrm{mL}^{-1} \\
N_{\mathrm{agg}}=10\end{array}$ & [45] \\
\hline POSS-PMMA ${ }_{144}-b-\mathrm{P}(\mathrm{MA}-\mathrm{POSS})_{2.6 ; 9.6 ; 11.3}$ & THF & - & $\begin{array}{l}R_{\mathrm{h}}=85 ; 148 ; 80 \mathrm{~nm} \\
\text { Core-shell micelles }\end{array}$ & [46] \\
\hline $\mathrm{PMMA}_{340 ; 400}-b-\mathrm{PtBMA}_{134}$ & - & 2-ethylhexanol & $\begin{array}{l}R_{\mathrm{h}}=19.4 \div 28.2 \mathrm{~nm} \\
\text { Spheres and cylinders }\end{array}$ & [47] \\
\hline PSAMA $_{15}-b$-P(Boc-Phe-HEMA) $)_{7 ; 17 ; 37 ; 75}$ & - & DMF; DMSO; ACN & $\begin{array}{c}R_{\mathrm{h}(\mathrm{DMF})}=119 \div 318 \mathrm{~nm} \\
R_{\mathrm{h}(\mathrm{DMSO})}=37 \div 90 \mathrm{~nm} \\
R_{\mathrm{h}(\mathrm{ACN})}=24 \div 48 \mathrm{~nm} \text { Spheres }\end{array}$ & [48] \\
\hline PEtOx $_{10}-b-\mathrm{PNBA}_{7 ; 17 ; 31 ; 48}$ & - & $\mathrm{CH}_{2} \mathrm{Cl}_{2}$ & $R_{\mathrm{h}}=45 \div 60 \mathrm{~nm}$ Spheres & [49] \\
\hline PVAc $_{57}-b$-(PFHE-stat-PVAc) 95 & $\mathrm{CH}_{3}-\mathrm{OH}$ & - & $R_{\mathrm{h}}=10 \div 40 \mathrm{~nm}$ Spheres & [50] \\
\hline 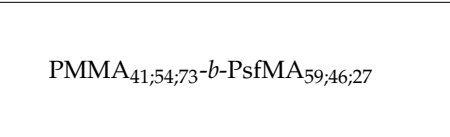 & THF; $\mathrm{ACN} ; \mathrm{CHCl}_{3}$ & - & $\begin{array}{c}N_{\mathrm{agg}(\mathrm{THF})}=8 \\
N_{\mathrm{agg}(\mathrm{CHCl} 3)}=26 \\
N_{\mathrm{agg}(\mathrm{ACN})}=410 \\
R_{\mathrm{h}(\mathrm{THF})}=60-70 \mathrm{~nm} \text { Spheres }\end{array}$ & [51] \\
\hline
\end{tabular}

The copolymers are designated by $\mathrm{PX}_{m, n}-\mathrm{PY}_{m^{\prime}, n^{\prime}}$, where $m, n, m^{\prime}$ and $n^{\prime}$ are the $D P_{\mathrm{n}}$ values. PNVP: poly(N-vinylpyrrolidone); POSS-PMMA: polyhedral oligomeric silsesquioxane-poly(methyl methacrylate); PSAMA: poly(2-(methacryloyloxy)ethyl stearate); P(Boc-Phe-HEMA): poly(tert-butyloxycarbonyl phenylalanine methacryloyloxyethyl ester); PEtOx: poly(2-ethyl-2-oxazoline); PNBA: poly(2-nitrobenzyl acrylate); PVAc: poly(vinyl acetate); PFHE: poly(perfluorohexylethylene); PsfMA: poly(1H,1H,2H,2H-perfluorodecyl methacrylate).

From Table 3, it appears that the interest of the authors was focused on the (meth)acrylic- and vinyl ester-based copolymers that might have practical industrial application possibilities. Furthermore, it can be noticed that solvents having a solubility parameter in the range of 18 to $30 \mathrm{MPa}^{1 / 2}$ (see Table 1), and in particular methanol, are suitable selective solvents.

\subsection{Self-Assembly of $A B$ and $A B A$ Block Copolymers in Organic Solvent Mixtures}

An alternative to pure organic solvents is provided by the mixtures of two solvents, which may allow for a gradual variation of the "solvent quality". Sophisticated morphologies of micellar nano-particles become accessible using this typical approach.

The influence of the "solvent quality" on micellar characteristics was studied by Cho et al. [52] for a poly(styrene)- $b$-P4VP:poly(4-vinyl pyridine) ( $\mathrm{PS}_{400}-b$ - $\left.\mathrm{P}_{4} \mathrm{VP}_{167}\right)$ diblock copolymer sample in pure $\mathrm{THF}$, THF/water, and THF/ethanol mixtures, respectively. The $R_{\mathrm{h}}$ of the micelles, with a P4VP core and PS corona, was around $23 \mathrm{~nm}$ in pure THF, significantly decreased to $14.1 \mathrm{~nm}$ for a solvent mixture composition of $95 / 5 \mathrm{v} / \mathrm{v} \% \mathrm{THF} / \mathrm{EtOH}$. Moreover, in the presence of ethanol, which is a "good solvent" for the P4VP core, micellar size polydispersity increased, whereas the aggregation number decreased.

Zhou et al. [53] investigated the self-assembly of poly(styrene)- $b$-PHFBMA:poly(2,2,3,3,4,4, 4-heptafluorobutyl methacrylate) (PS- $b$-PHFBMA) copolymers in a mixture of THF and ethyl acetate (EtOAc) at different volume ratios, such as 5:0; 4:1; 3:2; and, 0:5. For these mixtures, the authors calculated the solubility parameters in order to study their influence on the copolymer's self-aggregation behavior. As observed with TEM, the micellar morphology changed from spheres to 
vesicles with the increase in EtOAc content. By DLS, it turns out that the average size of the micelles increased from 140 to $190 \mathrm{~nm}, 235$ and $267 \mathrm{~nm}$, respectively, as a function of EtOAc volume fraction. Moreover, it was demonstrated by these authors that the morphology and the size of the micelles was highly influenced by the temperature.

Wang et al. [54] studied the self-aggregation of a $\mathrm{PS}_{64}-b-\mathrm{PEO}_{827}$ diblock copolymer in a mixture of cyclohexane/1,4-dioxane (80/20 wt \%), using DLS and TEM. For the preparation of the micellar solution, the copolymer was at first directly dissolved in 1,4-dioxane and then the cyclohexane was added very slowly. Spherical micelles with a $D_{\mathrm{h}}$ of $50 \mathrm{~nm}$ were obtained from this procedure. A micellar morphological transformation was observed, from spheres to cylinders and vesicles, by decreasing the temperature from 25 to $0{ }^{\circ} \mathrm{C}$ and then to $-10{ }^{\circ} \mathrm{C}$. This transformation from spheres to vesicles, attributed to the increasing interfacial energy between the solvent and the PEO core, was highly temperature dependent and accompanied by an increase in the $D_{\mathrm{h}}$ from 50 to $1680 \mathrm{~nm}$.

In addition to DLS and TEM techniques, the micellar morphological modifications were confirmed with SAXS. In this context, Rao et al. [55] investigated the self-aggregation of a $\mathrm{PS}_{481}-b$-P2 $\mathrm{VP}_{157}$ diblock copolymer in a mixture of dimethylformamide (DMF) and methanol in order to prepare micelle-functionalized silica particles. Core-shell spherical micelles, with a $R_{\mathrm{h}}$ value of $22.5 \mathrm{~nm}$, were obtained by direct dissolution of the copolymer in DMF, as a common solvent, followed by a slow addition of methanol.

Choi et al. [56] studied the self-assembly of $\mathrm{PS}_{404}-b$-PEP 886 diblock copolymers in a mixture of 1-phenyldodecane $\left(\delta=17.4 \mathrm{MPa}^{1 / 2}\right) /$ squalane $\left(\delta=16.6 \mathrm{MPa}^{1 / 2}\right)$. At $110^{\circ} \mathrm{C}$ and a $50 / 50$ ratio of 1-phenyldodecane/squalane, the micellar $R_{\mathrm{h}}$ was equal to $280 \mathrm{~nm}$, which is much higher than the value of $40 \mathrm{~nm}$ determined by Growney et al. [41] for the $\mathrm{PS}_{315}-b$ - $\mathrm{PEP}_{1203}$ micelles in $n$-heptane, at the same temperature. Due to this comparison, solvents, such as heptanes and $n$-decane with $\delta$ values of 15 to $16 \mathrm{MPa}^{1 / 2}$ appear to be more selective for PEP than the 1-phenyldodecane/squalane mixture, with an average $\delta$ value of around $17 \mathrm{MPa}^{1 / 2}$.

\subsection{Self-Assembly of $A B$ and ABA Block Copolymers in Ionic Liquids}

Ionic liquids (ILs), which are a special class of polar solvents, are interesting for environmental reasons when compared to common volatile organic solvents. In addition, excellent chemical and thermal stability, wide liquid temperature ranges, and low toxicity are the most important typical properties of ionic liquids. Due to these specific properties, ILs have become efficient solvents for the synthesis of block copolymers using the PISA technique, as outlined in a recent review by Derry et al. [57]. Moreover, the self-assembly of block copolymers in ILs has led to the development of original micellar structures. In connection with this topic, the recent relevant publications are listed in Table 4.

Table 4. Self-assembly studies of AB block copolymers in pure ionic liquids.

\begin{tabular}{|c|c|c|c|c|}
\hline AB Block Copolymers & $\begin{array}{l}\text { Selective Solvent } \\
\text { for A Block }\end{array}$ & $\begin{array}{l}\text { Selective Solvents } \\
\text { for B Block }\end{array}$ & Micellar Characteristics & Ref. \\
\hline $\mathrm{PEO}_{432}-b-\mathrm{PNIPAM}_{106}$ & $\begin{array}{l}{[\mathrm{BMIM}][\mathrm{BF} 4]} \\
\delta=24 \mathrm{MPa}^{1 / 2}\end{array}$ & - & $\begin{array}{c}R_{\mathrm{h}}=25 \mathrm{~nm} \\
\text { L.C.M.T }=200^{\circ} \mathrm{C} \\
\text { U.C.M.T }=60^{\circ} \mathrm{C}\end{array}$ & [58] \\
\hline $\mathrm{PS}_{529 ; 548 ; 981-b-\mathrm{P} 2 \mathrm{VP}_{543 ; 543 ; 923}}$ & - & $\begin{array}{c}\text { [BMIM][CF3SO3] } \\
\delta=25 \mathrm{MPa}^{1 / 2}\end{array}$ & Spherical micelles & [59] \\
\hline $\mathrm{PEO}_{341}-b-\mathrm{P}(\mathrm{AzoMA}-r \text {-NIPAM })_{177}$ & $\begin{array}{l}{[\mathrm{C} 4 \mathrm{MIM}][\mathrm{PF} 6]} \\
\delta=23 \mathrm{MPa}^{1 / 2}\end{array}$ & - & $R_{\mathrm{h}} \sim 120 \mathrm{~nm}$ & [60] \\
\hline $\mathrm{PEO}_{432}-b-\mathrm{PnBMA}_{99 ; 183}$ & $\begin{array}{l}\text { [BMIM][TFSI] } \\
\delta=26 \mathrm{MPa}^{1 / 2} \\
{[\mathrm{EMIM}][\mathrm{TFSI}]} \\
\delta=27 \mathrm{MPa}^{1 / 2}\end{array}$ & - & C.M.T $=120-150{ }^{\circ} \mathrm{C}$ & [61] \\
\hline
\end{tabular}


Table 4. Cont.

\begin{tabular}{|c|c|c|c|c|}
\hline AB Block Copolymers & $\begin{array}{l}\text { Selective Solvent } \\
\text { for A Block }\end{array}$ & $\begin{array}{l}\text { Selective Solvents } \\
\text { for B Block }\end{array}$ & Micellar Characteristics & Ref. \\
\hline $\begin{array}{c}\text { PEGE }_{109 ; 113 ; 104}-b-\mathrm{PEO}_{54 ; 115 ; 178} \\
\text { PGPrE }_{98}-b-\mathrm{PEO}_{260}\end{array}$ & $\begin{array}{c}\text { PAN; EAN } \\
\delta=25-26 \mathrm{MPa}^{1 / 2}\end{array}$ & - & $\begin{array}{c}\text { spherical micelles for } \\
\text { PEO }_{178}-b \text {-PEGE } \\
\text { Disk-shape micelles for } \\
\text { PEO }_{54}-b-\text { PEGE }_{109}\end{array}$ & [62] \\
\hline $\mathrm{PEGE}_{104}-b-\mathrm{PEO}_{178}$ & $\begin{array}{l}{[\mathrm{C} 4 \mathrm{MIM}][\mathrm{PF} 6]} \\
\delta=23 \mathrm{MPa}^{1 / 2}\end{array}$ & - & $R_{\mathrm{h}}=13 \mathrm{~nm}$ & {$[63]$} \\
\hline PMMA $_{250}-b$-PnBMA92;169;218;246;310;373;549 & $\begin{array}{l}\text { [EMIM][TFSI] } \\
\text { [BMIM][TFSI] }\end{array}$ & - & $\begin{array}{c}R_{\mathrm{h}}=17.8 \div 34.6 \mathrm{~nm} \\
R_{\text {core }}=5.8 \div 23.2 \mathrm{~nm} \\
N_{\text {agg }}=41 \div 432\end{array}$ & {$[64,65]$} \\
\hline
\end{tabular}

L.C.M.T and U.C.M.T: lower and upper critical micellization temperature; PNIPAM: poly( $N$-isopropylacrylamide); P(AzoMA): poly(4-phenylazophenyl methacrylate); PEGE: poly(ethyl glycidyl ether); PGPrE: poly(glycidyl propyl ether); [BMIM][CF3SO3]: 1-butyl-3-methylimidazolium trifluoromethanesulfonate; [C4MIM][PF6]: 1-butyl-3-methylimidazolium hexafluorophosphate; EAN: ethylammonium nitrate; PAN: propylammonium nitrate.

In addition to Table 4, typical and detailed examples are given to highlight the correlation between the micellar characteristics and the major system parameters, such as the relative sequence length of the copolymers, and, in particular, the respective solvent/copolymer solubility parameter.

Simone and Lodge [66] studied, by cryo-TEM and DLS, the self-assembly of a series of three PS-b-PMMA block copolymers with different compositions in 1-butyl-3-methylimidazolium hexafluorophosphate [BMIM][PF6]. This ionic liquid, with a $\delta$ value of $30 \mathrm{MPa}^{1 / 2}$, is a selective solvent for the PMMA block. The reduction of the PMMA content leads to a morphological transition from spherical to cylindrical micelles. More recently, for the same type of hydrophobic/hydrophobic PS- $b$-PMMA block copolymer, Mok et al. [67] investigated the effect of the composition on the C.M.C in 1-ethyl-3-methylimidazolium bis(trifluoromethylsulfonyl)imide [EMIM][TFSI], an IL with a $\delta$ value of $27 \mathrm{MPa}^{1 / 2}$. A decrease in the C.M.C values from 0.40 to $0.078 \mathrm{wt} \%$ was observed when the $D P_{\mathrm{n}}$ of the PS-core increased from 29 to 106.

The micellization in [BMIM][PF6] ionic liquid of a series of hydrophobic/hydrophilic PB-b-PEO diblock copolymers, with fixed PB and increasing PEO sequence lengths, was investigated by He et al. [68]. By increasing the molar fraction of the PEO, micellar morphology evolved from worm-like micelles and bilayered vesicles to spheres. An illustration of these morphologies determined by cryo-TEM is provided in Figure 3.
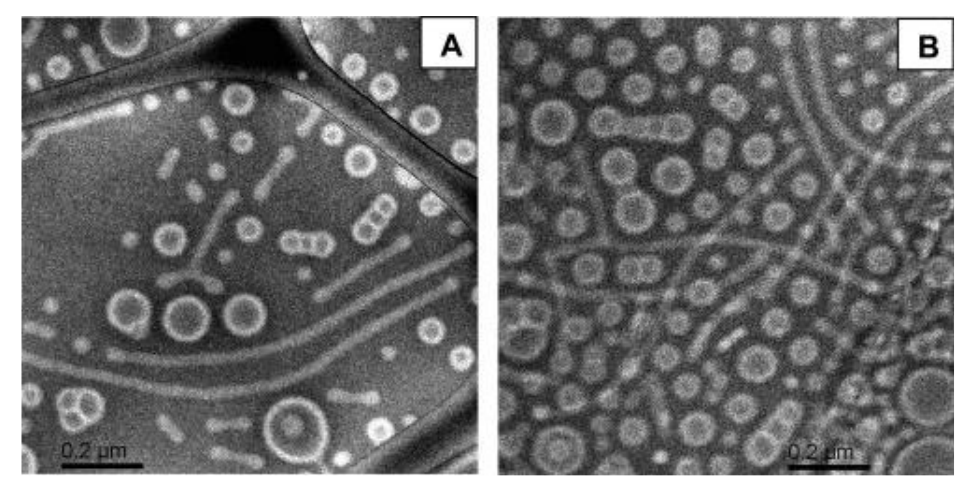

Figure 3. Cryo-TEM images of PB- $b$-PEO copolymer, with $0.25 \mathrm{~mol} \% \mathrm{PEO}$, at a concentration of $1 \mathrm{wt} \%$ in [BMIM][PF6]. (A) Worm-like micelles with occasional Y-junctions and (B) micellar overlap. "Reprinted with permission from He, Y.; Li, Z.; Simone, P.; Lodge, T.P. Self-assembly of block copolymer micelles in an ionic liquid. J. Am. Chem. Soc. 2006, 128, 2745-2750. Copyright 2017 Americal Chemical Society".

More recently, the micellization of a quite similar PB- $b$-PEO copolymer series was investigated by Meli et al. [69] in [EMIM][TFSI] ionic liquid. These authors demonstrated that the direct dissolution 
of the copolymer led to the formation of large aggregates. However, a thermal treatment at $170{ }^{\circ} \mathrm{C}$ induced the formation of spherical micelles with $R_{\mathrm{h}}$ values of around $29 \mathrm{~nm}$. For a given copolymer sample, it was of interest to compare the influence of the solubility parameter of both the PB-core and the solvent on the micellar characteristics. For this purpose, the authors studied the self-aggregation in a different IL, such as 1-butyl-3-methylimidazolium bis-(trifluoromethyl sulfonyl)imide [BMIM][TFSI], which has a slightly smaller $\delta$ value $\left(26.7 \mathrm{MPa}^{1 / 2}\right.$ when compared to $27.6 \mathrm{MPa}^{1 / 2}$ for [EMIM][TFSI]). Similar micellar characteristics were obtained for these two ILs. This experiment, performed with two different ILs with similar $\delta$ values, confirms that the $\delta$ value of the solvent is the key parameter in the macromolecular self-association process.

The self-assembly of ABA copolymers in ILs was predominantly investigated for PEO- $b$-PPO- $b$-PEO copolymers, also designated as Pluronics. Zhang et al. [70] determined the C.M.C values of three Pluronics with a constant PPO sequence length, such as $\mathrm{L61}\left(\mathrm{PEO}_{3}-\mathrm{PPO}_{30}-\mathrm{PEO}_{3}\right)$, L64 ( $\left.\mathrm{PEO}_{13}-\mathrm{PPO}_{30}-\mathrm{PEO}_{13}\right)$ and $\mathrm{F} 68\left(\mathrm{PEO}_{79}-\mathrm{PPO}_{30}-\mathrm{PEO}_{79}\right)$, in both 1-butyl-3-methylimidazolium tetrafluoroborate [BMIM][BF4] $\left(\delta=24 \mathrm{MPa}^{1 / 2}\right)$ and [BMIM][PF6] $\left(\delta=30 \mathrm{MPa}^{1 / 2}\right)$ ionic liquids. These authors found that the critical micellar concentrations increased as expected with the PEO sequence length. As an extension of these results, Lopes-Barron et al. [71] studied the self-association in deuterated ethylammonium nitrate (dEAN) of a similar series of Pluronics, such as F127 $\left(\mathrm{PEO}_{106}-\mathrm{PO}_{70}-\mathrm{PEO}_{106}\right), \mathrm{P} 123\left(\mathrm{PEO}_{20}-\mathrm{PPO}_{70}-\mathrm{PEO}_{20}\right)$ and $\mathrm{L} 121\left(\mathrm{PEO}_{5}-\mathrm{PPO}_{70}-\mathrm{PEO}_{5}\right)$. Pluronic samples with higher PEO/PPO molar ratios (F127 and P123) promoted the formation of spherical micelles, whereas small PEO/PPO ratios (L121) favor the formation of vesicles.

\subsection{Self-Assembly of $A B$ and $A B A$ Block Copolymers in Biocompatible Organic Solvents}

Among the above-mentioned non-aqueous block copolymer micellar systems, a large number may be considered as biocompatible. This especially occurs with block copolymer micelles in saturated aliphatic hydrocarbon solvents, such as $n$-decane, dodecane, etc. Another typical example of a non-aqueous self-assembly study was reported by Miller et al. [72] for poly(caprolactone)- $b$-poly(2-vinylpyrridine) (PCL-b-P2VP) copolymers in oleic acid, a biocompatible natural fatty acid. Spherical micelles, with a PCL core and an average size of $144 \mathrm{~nm}$, were observed from the cryo-TEM images. Moreover, these authors investigated the loading of two model proteins into this micellar system.

Our research group studied the micellization of P2VP- $b$-PEO diblock copolymers in several biocompatible solvents, such as PEG400 $\left(\delta=21.3 \mathrm{MPa}^{1 / 2}\right)$, paraffin oil $\left(\delta=15.3 \mathrm{MPa}^{1 / 2}\right)$, and Miglyol $812\left(\delta=17.3 \mathrm{MPa}^{1 / 2}\right)$ [73-75]. Spherical micelles, having a P2VP core and a $R_{\mathrm{h}}$ in the range of 23 to $25 \mathrm{~nm}$ were obtained by the self-assembly of $\mathrm{P}_{2} \mathrm{VP}_{37}-b-\mathrm{PB}_{189}$ copolymer sample in paraffin oil and Miglyol 812, which is a glycerine ester. However, micelles with a higher $R_{\mathrm{h}}$ of around $60 \mathrm{~nm}$ and a PB core, were formed in PEG400. The driving force for the self-assembly of these diblock copolymers is the polymer/solvent interaction parameter $\chi$. Notably, block copolymer micellar systems based on natural oils, such as Miglyol 812, may be used for biomedical or cosmetic applications [73].

\subsection{Crystallization-Induced Self-Assembly of $A B$ and ABA Block Copolymers in Organic Solvents}

Block copolymers that include a crystallizable sequence may lead to micelles having a partially crystallized core. This so-called "crystallizable-driven self-assembly" (CDSA) method was reviewed by different authors [76,77], and more recently, by Tritschler et al. [27]. This process, involving phase separation above the melting temperature $\left(T_{\mathrm{m}}\right)$ and crystallization upon cooling, leads to a partially crystallized micellar core that is stabilized by the soluble sequence of the copolymer. By using this method, the groups of Winnik and Manners have obtained sophisticated and precise rod-coil micellar structures in organic solvents with well-controlled dimensions [27-29]. The width and the shape of these non-spherical micelles could be modified by varying the $D P_{\mathrm{n}}$ of the crystalline micellar core, the composition of the corona or the experimental conditions.

Anexample of crystallizable $\mathrm{PB}_{54}-b-\mathrm{PEO}_{61}$ block copolymer was studied by Mihut et al. [78] in $n$-heptane, which is a "good solvent" for PB. At $70{ }^{\circ} \mathrm{C}$ micelles are formed with a PEO core and PB 
corona, with an $R_{\mathrm{h}}$ of $12 \mathrm{~nm}$. Upon cooling to $20^{\circ} \mathrm{C}$, a size increase to $140 \mathrm{~nm}$ was observed by DLS as a direct consequence of the PEO core crystallization. A similar example of crystallization-induced self-aggregation concerns the micellar solutions of poly(methylene)- $b$-poly(acrylic acid) (PM- $b$-PAA) block copolymer in DMF, which was reported by Wang et al. [79]. At $80{ }^{\circ} \mathrm{C}$, the copolymer is molecularly dispersed in DMF. On cooling, the PM block crystallizes and self-aggregates into well-defined disk-like structures. In a further recent example, another research group [80] has studied the self-assembly of P2VP-b-PEO in a $n$-amyl acetate $\left(\delta=17.4 \mathrm{MPa}^{1 / 2}\right) / n$-butanol $\left(\delta=23.1 \mathrm{MPa}^{1 / 2}\right)$ mixture. At $35{ }^{\circ} \mathrm{C}$, these authors observed the formation of spherical micellar morphologies having a partially crystallizable PEO corona with a size of around $200 \mathrm{~nm}$. With a fast temperature decrease, well-defined single crystals were obtained by crystallization of the PEO block. Recently, the groups of Winnik and Manners [81] studied the self-assembly of two amphiphilic crystalline-coil polyferrocenyldimethylsilane- $b$-poly( $N$-isopropylacrylamide) (PFS- $b$-PNIPAM) diblock copolymers in methanol, ethanol, and 2-propanol. Spherical micelles were formed in methanol and ethanol for the $\mathrm{PFS}_{56}-b$-PNIPAM 190 sample whereas a mixture of spherical and cylindrical structures were noticed for this sample in 2-propanol. This behavior, which was also observed for PFS- $b$-P2VP copolymers, was probably due to the different solubility of the PFS in these solvents.

\subsection{Concluding Remarks}

To make conclusions about the literature survey concerning the self-assembly of polyA-b-polyB diblock copolymers, the aim of the present section is to provide a critical analysis of the published results. Moreover, our intention is to highlight the recent advances and trends that were observed in different steps of the self-assembly process of diblock copolymers in organic solvents.

For $\mathrm{AB}$ and $\mathrm{ABA}$ diblock copolymers, the recent investigations were focused on the synthesis of "well-defined" samples, with low polydispersity indices in composition and molecular weight. Although sequential anionic polymerization remains a favorite and well adapted synthesis technique, the so-called "controlled free radical" methods (RAFT, ATRP, NMP ... ) are now used to a large extent. In fact, these recent techniques have the advantage to provide access to a broader range of block copolymer types, in particular to those based on polar monomers. Among the recent synthesis trends, mention has to be made for the PISA process, which involves, in the polymerization step, the formation of a micellar system in organic solvent. A further synthesis trends concerns the preparation of end-functionalized and fluorescent labeled AB diblock copolymers. With respect to the determination of the molecular characteristics, NMR and SEC remain the "classical" analytic techniques. Unfortunately, quite a number of studies are published with indication of the "equivalent $P S^{\prime}$ number and weight average molecular weights of their products. Precise and actual molecular weight values of the copolymer sample would be accessible by SEC and simultaneous determination of the intrinsic viscosity [ $\eta$ ]. Such multi-detector SEC devices with so-called "universal calibration" are presently standard equipments. In addition to SEC technique, diffusion ordered spectroscopy (DOSY), recently reviewed by Groves [82], could be a valuable tool to detect polyA and/or polyB homopolymer "impurities" in a synthesized polyA-b-polyB block copolymer.

As already previously mentioned in Section 2, most of the published micellar systems may be considered from a thermodynamic point of view as non-equilibrium systems between unimers and micelles. The characteristics, such as size and morphology of these "frozen-in" nanoparticles will depend to a large extend on their preparation procedure. The experimental conditions may in fact vary from a simple dissolution of the sample to an elaborated precipitation procedure in a selective solvent of either the polyA or polyB block of the copolymer. It has to be recalled that the most usual procedure consists in the solubilization of the copolymer in a common solvent. To this molecular dispersion is then added drop-wise the selective solvent of either the A or B block and the common solvent is then eliminated, in general, by dialysis, in order to end up with micelles dispersed in a pure selective solvent. 
Among the recent trends in self-assembly techniques, mention has to be made of the preparation procedure involving solvents mixtures, either mixtures of two organic solvents or of an organic solvent and water. This type of approach has the advantage that the solubility parameter and the solvent/polymer interaction parameter $\chi$ may be triggered step by step as a function of the volume fraction of the two solvents in presence. From the studies concerning the self-assembly in organic solvents mixtures, mentioned in Section 3.3, it could be noticed that these mixtures have a strong influence on particle size and morphology. A first type of approach, illustrated by Zhou et al. [53], is to generate a solvent mixture, having a solubility parameter $\delta_{\mathrm{mix}}$, adapted as a selective solvent for either the $\mathrm{A}$ of $B$ block of the $A B$ copolymer. In a first approximation, it may be assumed that $\delta_{\text {mix }}=\varnothing_{1} \delta_{1}+\varnothing_{2} \delta_{2}$, with $\varnothing_{1}$ and $\varnothing_{2}$ the volume fractions and $\delta_{1}, \delta_{2}$ the solubility parameters of the two solvents. The major limitation of this concept is that both solvents have to be selective solvents of either the A of the B block. If this requirement is not met, then a partition of the solvents may occur, which leads to a swelling of the micellar core by either one or both solvents in presence. A second possibility to use organic solvent mixtures in the self-assembly process of polyA- $b$-polyB copolymers was investigated by different authors [54-56]. Their approach consists in the solubilization of the copolymer in a common solvent $S$, a "good" solvent for both polyA and polyB sequences. To this molecularly dispersed copolymer is then added a given amount of selective solvent, such as for instance a solvent $S_{A}$ selective for the polyA block. This procedure leads to the precipitation of the polyB block and to the formation of micelles having a polyB core more or less swelled by the common solvent $S$, as schematically illustrated in Figure 4 . These micelles are stabilized by the polyA sequence solubilized in the $S+S_{A}$ solvent mixture. The presence of the common solvent $S$ in the final micellar system represents the major difference with respect to the "classical" systems, where the common solvent is eliminated, in general, by dialysis, in the final preparation stage.

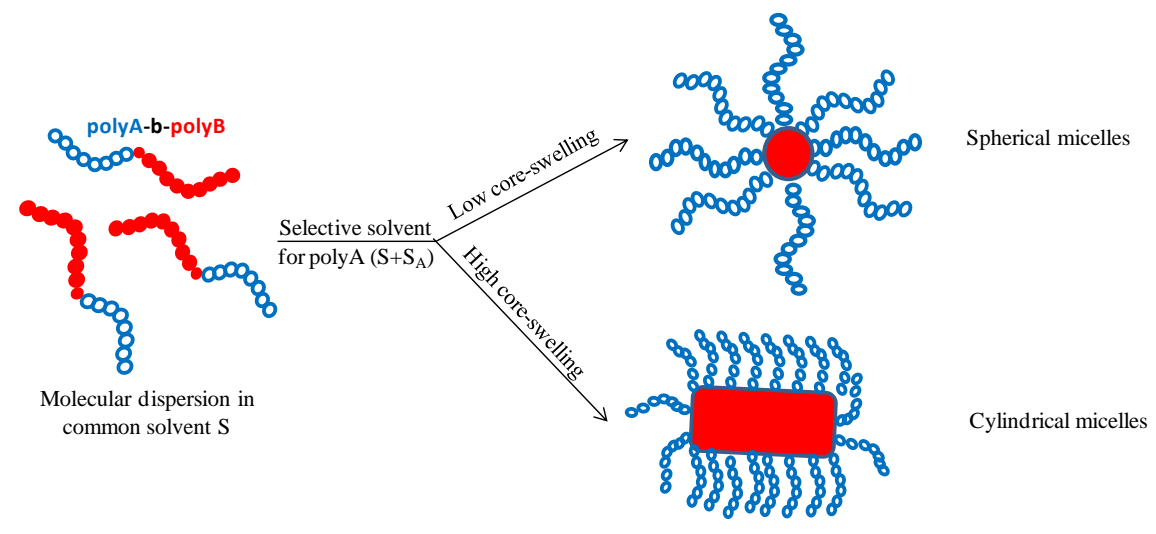

Figure 4. Schematization of the polyA-polyB diblock copolymer self-assembly process in solvents mixture.

For polyA-b-polyB micellar systems in a selective solvent it is now well established that the spherical, cylindrical, and vesicular morphology is mainly determined by the relative volume fractions of the core and corona. Spherical morphologies, for instance, are in general generated when $D P_{\mathrm{A}}$, the polymerization degree of the polyA sequence, is low with respect to $D P_{\mathrm{B}}$ (the corona forming block). In the case of solvent mixtures, the relative volume fractions of core and corona are mainly determined by their swelling characteristics as a function of the solvent compositions and temperature. At a given temperature, spherical micelles have a tendency to be formed at a lower swelling degree of the micellar core. At this point, there is still a lack of information concerning: (i) the onset of self-assembly as a function of the molecular characteristics of the copolymer; (ii) the evaluation of the copolymer conformation with increasing selective solvent concentration; (iii) the partition of common and selective solvents in the micellar core and corona; and, (iiii) the evolution of the swelling degree of the core as a function of the volume fraction of the solvents. Regarding the self-assembly in 
solvents mixtures, it is established that this process opens interesting perspectives for the development of new morphologies and it could also provide an important insight in the "classical" self-assembly process itself.

In our opinion, the scattering and electron microscopy for micellar characterization techniques are well documented in the literature. As a minor point, it might be suggested that the DLS characterizations should be carried out as a function of concentration, with extrapolation to zero concentration. The determination of the interphase, the dimensions of the transition zone between core and corona, could be of interest for specific applications, such as those where micellar systems are used as nanoreactors. Finally, it is quite surprising that in contrast to water-based micellar systems, only very few results were published concerning the CMC and CMT values of block copolymers in organic solvents. A similar remark can be made for the determination of the aggregation number $N_{\text {agg, }}$, the average number of polymer chains per micelles.

The "crystallization-induced self-assembly" topic, including rod-coil and other micellar structures, was very recently reviewed by Tritschler et al. [27]. This self-assembly method offers the possibility to prepare non-spherical micellar morphologies with controlled dimensions having promising applications in various domains.

\section{Self-Assembly of Linear ABC Triblock Terpolymers in Organic Solvents}

Linear $\mathrm{ABC}$ triblock terpolymers have opened an extensive research area for the development of sophisticated micellar structures over the last decade. Up to now, several excellent review papers have been published on this topic $[2,7,83]$. For the self-assembly of $A B C$ copolymers it turns out once again that a majority of the studies were focused on aqueous-based micellar systems and only relatively few of them on the micellization in organic media. Wyman and Liu [83], for instance, showed the fascinating morphologies that are becoming available for a given $\mathrm{ABC}$ copolymer by precise control of the micellization conditions, including the solvent mixtures. More recently, Gröschel and Müller [84] extended this review by providing a detailed insight of the multi-compartment nanostructures that are accessible, as well with $\mathrm{AB}$ and $\mathrm{ABC}$ triblock terpolymers.

The objective of this chapter is to highlight the recent developments, including the present author's contributions, of $\mathrm{ABC}$ triblock terpolymer micellar systems generated in organic solvents. Polar and non-polar solvents will be taken into consideration, as well as mixtures of organic solvents. According to Wyman and Liu [83], the basic micellar spherical morphologies of ABC triblock terpolymers are outlined in Figure 5, as a function of the solvent selectivity.

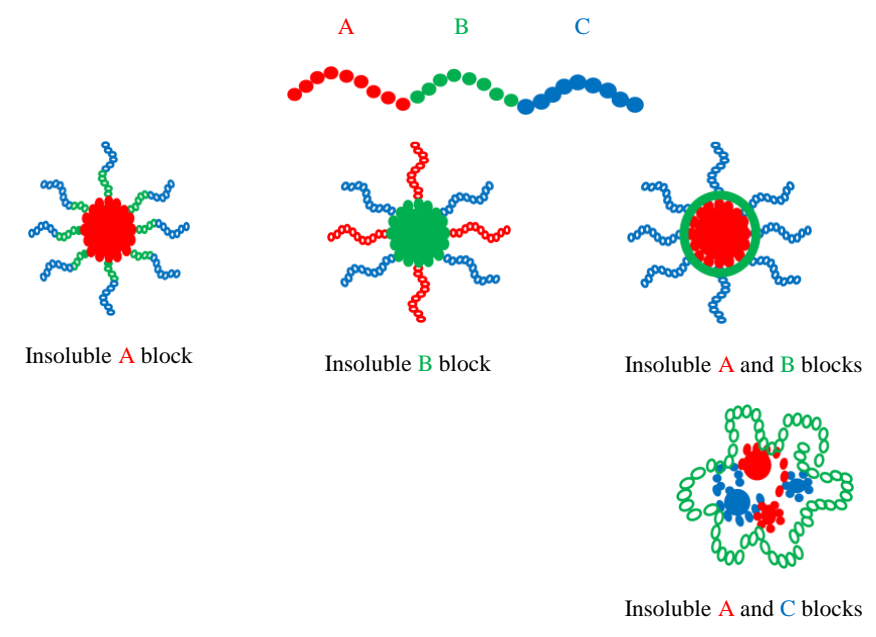

Figure 5. Basic micellar morphologies for linear ABC triblock terpolymers.

The sequence organization, as schematically displayed in Figure 5 for spherical micelles, is similar for cylindrical (worm-like) and vesicle micellar morphologies. 
For ABC-type linear triblock terpolymers, the sequence arrangement is an additional parameter that must be considered with respect to diblock copolymers. In fact, for a given ABC sample in selective solvent conditions, the micellar characteristics are different from the corresponding $\mathrm{ACB}$ and BAC structures. Up to now, the effect of the sequence arrangement was demonstrated for the self-assembly of triblock terpolymers in aqueous media $[85,86]$ or in water/organic solvent mixtures [87]. Marsat et al. [85] examined the micellar formation in aqueous medium of an $\mathrm{ABC}, \mathrm{ACB}$, and $\mathrm{BAC}$ triblock terpolymer comprising a hydrophilic, a hydrophobic, and a fluorophilic sequence, such as poly[oligo(ethylene oxide) monomethyl ether acrylate]-poly(benzyl acrylate)-poly $(1 \mathrm{H}, 1 \mathrm{H}$-perfluorobutyl acrylate) (POEGA-PBzA-PFA). The chemical structure of this ABC copolymer is shown in Figure 6.

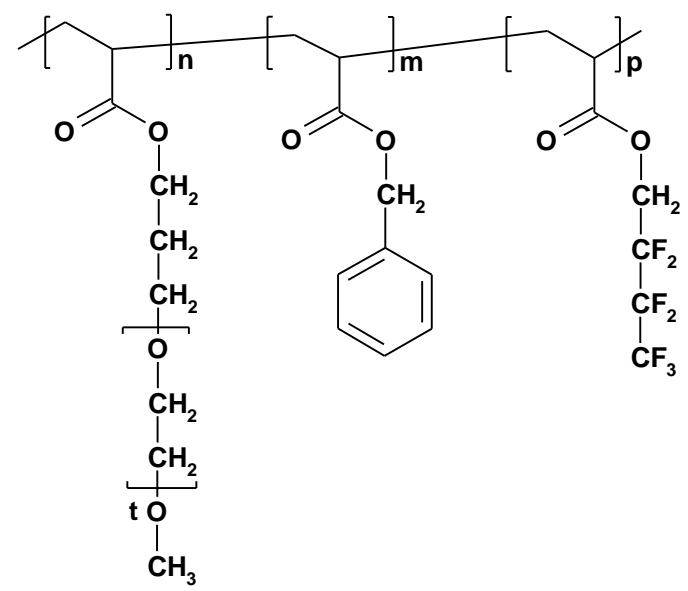

Figure 6. Chemical structure of the ABC triblock terpolymer POEGA-PBzA-PFA [85].

Analogous to the previous chapter, the present one will be organized in a similar way by considering the self-assembly of $\mathrm{ABC}$ triblock terpolymers in non-polar, polar, and solvent mixtures. This means that a given $\mathrm{ABC}$ copolymer may appear in different subsections.

\subsection{Self-Assembly of Linear ABC Triblock Terpolymers in Non-Polar Selective Solvents}

A typical example of self-assembly in non-polar solvent has been studied in our research group for a series of PB-P2VP-PEO triblock terpolymers in $n$-heptane, a selective solvent of the PB sequence, as well as in aqueous medium $[7,88,89]$.

This type of $\mathrm{ABC}$ copolymers has been selected as the solubility parameter of the sequences is well differentiated, such as 17,21 , and $20.8 \mathrm{MPa}^{1 / 2}$ for the PB, P2VP, and PEO, respectively. Moreover, the P2VP sequence is easily protonated or quaternized, yielding a $\mathrm{pH}$ - and electrolyte-sensitive water-soluble block. Figure 7 illustrates the variation of the micellar particle size as a function of the total $D P_{\mathrm{n}}$. 


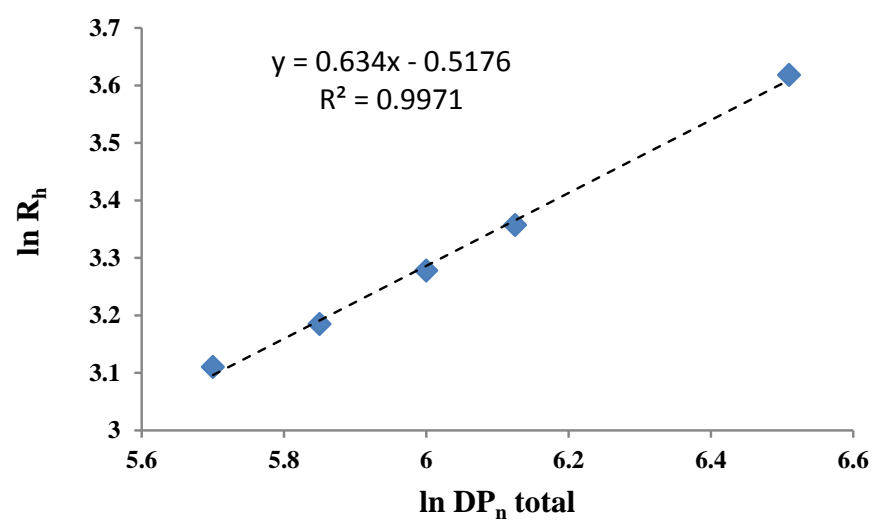

Figure 7. Logarithmic variation of the $R_{\mathrm{h}}$ as a function of $D P_{\mathrm{n}}$ total of PB-P2VP-PEO triblock terpolymers in $n$-heptane [88].

From Figure 7 , it can be noticed that $R_{h}$ scales as $D P_{n}{ }^{0.64}$ in reasonable agreement with the exponent of 0.68 predicted by Noolandi and Hong [90] for diblock copolymers. In a simplified approach, the $R_{\mathrm{h}}$ values could further be correlated with the individual $D P_{\mathrm{n}}$ values of the copolymers [88]. From a practical point of view, it was demonstrated that PB-P2VP-PEO copolymers with a P2VP middle block are efficient dispersing and stabilizing agents for $\mathrm{TiO}_{2}$ pigments in non-aqueous as well as in aqueous media [89]. Another example of the self-assembly studies of P2VP-based copolymers investigated in our research group was the micellization of poly(2-vinyl pyridine)-poly(tert-butyl methacrylate)-poly(cyclohexyl methacrylate) (P2VP-PtBMA-PCHMA) triblock terpolymers in methylcyclohexane, which are of practical interest as "viscosity improvers in motor-oil formulations" [7].

The self-assembly of P2VP-based triblock terpolymers, such as PS-P2VP-PMMA, was also studied by Tsitsilianis and Sfika [91] in toluene, a selective solvent for the PS and PMMA sequences. These authors found that both the $N_{\mathrm{agg}}$ and $R_{\mathrm{h}}$ of spherical core-shell micelles, having a P2VP-core and a corona of PS and PMMA, depend on the $D P_{\mathrm{n}}$ of the insoluble P2VP sequence. Core-shell micelles, based on amino (meth)acrylates, were also obtained by Bütün et al. [92] for poly[2-(diisopropylamino)ethyl methacrylate]-poly[2-(dimethylamino)ethyl methacrylate]-poly[2-( $N$-morpholino)ethyl methacrylate] (PDPA-PDMA-PMEMA) triblock terpolymers in hexane. In this case, the PDMA and PMEMA sequences are in the core of the micelles, which have a $R_{\mathrm{h}}$ of $46 \mathrm{~nm}$, whereas the PDPA block formed the solvated corona.

\subsection{Self-Assembly of Linear ABC Triblock Terpolymers in Polar Selective Solvents}

The recent publications concerning the self-assembly of linear $\mathrm{ABC}$ triblock terpolymers in polar solvents are summarized in Table 5.

Table 5. Self-assembly of linear ABC triblock terpolymers in polar solvents.

\begin{tabular}{|c|c|c|c|c|c|}
\hline ABC Triblock Terpolymers & $\begin{array}{l}\text { Selective Solvent } \\
\text { for A Block }\end{array}$ & $\begin{array}{l}\text { Selective Solvent } \\
\text { for B Block }\end{array}$ & $\begin{array}{l}\text { Selective Solvent } \\
\text { for C Block }\end{array}$ & Micellar Characteristics & Ref. \\
\hline PtBA $_{107}-b-$ PCEMA $_{193}-b-$ PGMA $_{115}$ & $\mathrm{CH}_{3}-\mathrm{OH}$ & - & $\mathrm{CH}_{3}-\mathrm{OH}$ & Vesicles and cylinders & [93] \\
\hline 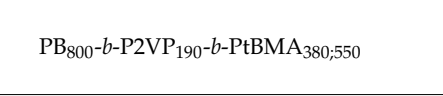 & Acetone & - & - & $\begin{array}{l}R_{\mathrm{h}}=43 ; 44 \mathrm{~nm} \\
R_{\mathrm{g}}=34 ; 36 \mathrm{~nm} \\
N_{\mathrm{agg}}=203 ; 174\end{array}$ & [94] \\
\hline 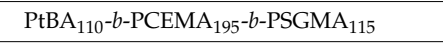 & Propanol & - & - & Cylinders & [95] \\
\hline $\mathrm{PS}_{385}-b-\mathrm{PI}_{485}-b-\mathrm{P}_{2} \mathrm{VP}_{829}$ & - & - & $\mathrm{C}_{2} \mathrm{H}_{5}-\mathrm{OH}$ & Ellipsoid & [98] \\
\hline
\end{tabular}

PtBA: poly(tert-butyl acrylate); PCEMA: poly(2-cinnamoyloxyethyl methacrylate); PGMA: poly(glyceryl monomethacrylate); PSGMA: poly(sucinnated glyceryl monomethacrylate); PnBA: poly( $n$-butyl acrylate); DMAc: dimethylacetamide. 
From Table 5, it may be noticed that the recent investigations concerning the self-assembly in polar solvents were mainly focused on alcohols, such as methanol, which is a selective solvent of the end-blocks. This implies that the middle block preferentially forms the micellar core.

\subsection{Self-Assembly of Linear ABC Triblock Terpolymers in Organic Solvent Mixtures}

The self-assembly of $\mathrm{ABC}$ terpolymers in organic solvent mixtures was performed essentially through the precipitation method starting from a homogeneous solution in a common solvent for all three blocks, followed by the addition of a non-solvent. As previously described, Bütün et al. [92] studied the self-assembly of two PDPA-PDMA-PMEMA triblock terpolymers, not only in $n$-hexane, but also in a mixture of $\mathrm{CHCl}_{3} / n$-hexane, starting from a unimer's solution in $\mathrm{CHCl}_{3}$. In this case, core-shell-corona micelles were obtained with a PMEMA core and a $R_{\mathrm{h}}$ value of $15 \mathrm{~nm}$.

The morphology of core-shell-corona structures, formed by the self-assembly of PS-P4VP-PEO triblock terpolymers in DMF/ethanol mixtures, was reported by Wang et al. [99] as a function of temperature. A further interesting study concerning the morphological behavior as a function of the "solvent quality" was performed by Löbling et al. $[97,100]$ for a series of PS-PB-PMMA and PS-PB-PtBMA triblock terpolymers in acetone/isopropanol mixtures. The micellar morphology modifications determined by cryo-TEM as a function of the isopropanol content are illustrated in Figure 8.
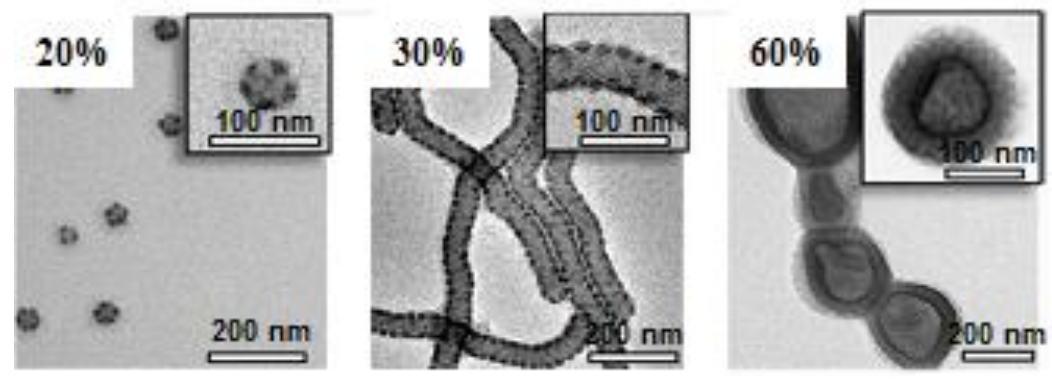

Figure 8. Micellar morphological changes of PS-PB-PMMA triblock terpolymers in acetone/isopropanol mixtures as a function of isopropanol content. "Reprinted with permission from Löbling, T.I.; Ikkala, O.; Gröschel, A.H.; Müller, A.H.E. Controlling multicompartment morphologies using solvent conditions and chemical modification. ACS Macro Lett. 2016, 5, 1044-1048. Copyright 2017 Americal Chemical Society".

More recently, Cong et al. [98] completed a similar study for PI-PS-P2VP triblock terpolymers in THF/ethanol mixtures.

\subsection{Miscellaneous Self-Assembly Studies of Linear ABC Triblock Terpolymers}

Given this context, and in analogy to $\mathrm{AB}$ diblock copolymers, studies have been completed on the behavior of $\mathrm{ABC}$ self-assembly in ionic liquids, the influence of partially crystallized moieties, and the development of biocompatible or thermo-sensitive systems.

Self-assembly of AB diblock copolymers in ILs has been studied extensively, as shown in Section 3. However, it seems that up to now ABC triblock terpolymers have attracted less attention. Mention could be made only of the publication of Kitazawa et al. [101]. These authors investigated the morphological behavior of a poly(benzyl methacrylate)-poly(methyl methacrylate)-poly(2-phenylethyl methacrylate) (PBnMA-PMMA-PPhEtMA) triblock terpolymer, as a function of temperature in 1-ethyl-3-methylimidazolium bis(trifluoromethanesulfonyl)amide [C2MIM][NTF2] $\left(\delta \sim 26 \mathrm{MPa}^{1 / 2}\right)$ at high copolymer concentrations, such as 10 and $20 \mathrm{wt} \%$.

The groups of Winnik and Manners have extended the CDSA method from AB diblock copolymers to $\mathrm{ABC}$ triblock terpolymers by studying the morphology of a series of well-defined coil-crystalline-coil poly(ferrocenylphenylphosphine)-poly(ferrocenyldimethylsilane)-poly 
(dimethylsiloxane) (PFP-b-PFS- $b$-PDMS) terpolymers in hexane, which is a selective solvent for PDMS [102]. Cylindrical micelles were obtained for the sample having the $D P_{n}(P F P)<6$, whereas spherical micelles were observed if the $D P_{n}(P F P)=11$. The longer PFP chains hinder the crystallization of the PFS sequence leading thus to the formation of spherical morphologies. More recently, the crystallization-induced self-assembly of poly(styrene)-poly(ethylene)-poly(methyl methacrylate) (PS-PE-PMMA) triblock terpolymer in toluene and dioxane, a good and bad solvent for the semicrystalline PE, respectively, was investigated by Schmelz et al. [103]. As a function of the "solvent quality", either spherical or worm-like crystalline-core micelles were observed by these authors.

The self-assembly of $\mathrm{ABC}$ triblock terpolymers in biocompatible non-aqueous solvents was investigated in our research group for a PB-P2VP-PEO sample. At low concentrations in PEG400, this triblock terpolymer forms spherical micelles with a PB-core and P2VP/PEO corona. An interesting feature appeared at concentrations higher than $3 \mathrm{wt} \%$, at which a thermo-reversible gel, due to the formation of $\mathrm{H}$-bonds, was noticed for these micellar systems [104].

\subsection{Concluding Remarks}

It is undeniable that $\mathrm{ABC}$ triblock terpolymers have opened an important research area, in particular for the development of sophisticated micellar morphologies. This topic having recently be reviewed in detail, the aim of the present section is to highlight more specific aspects related to the synthesis and the self-assembly of $\mathrm{ABC}$ linear triblock terpolymers. A very large range of this type of copolymers has been prepared up to now. In our opinion, it would be of interest for further developments of the field to synthesize homologous series of $\mathrm{ABC}, \mathrm{BCA}$, and $\mathrm{BAC}$ structures in order to complete the demonstration that the sequence distribution has a major influence on the micellar characteristics. For this type of copolymers, it would further worthwhile to check in different selective solvents the CMC, CMT values, as well as the $N_{\mathrm{agg}}$, which are scarcely reported up to now.

In the same manner as for $\mathrm{AB}$ diblock copolymers, the self-assembly of $\mathrm{ABC}$ copolymers in solvent mixtures could contribute to the understanding of the micellization process. This type of studies may be carried-out in specific solvent mixtures, as already demonstrated by different authors $[85,90,97]$. In order to complete the results reported by Zhang et al. [87] and by Bethausen et al. [105], it could be of interest to examine in detail the self-assembly of $\mathrm{ABC}$ terpolymers in solvent/water mixtures. Of further interest will be the self-assembly studies of $A B C$ terpolymers in ionic liquids and biocompatible organic solvents, which are only very scarcely discussed in the literature.

Crystallization of $A B C$ terpolymers in bulk, thin films and on surface, such as two-dimensional (2D) has been examined in detail over the last years. However, in comparison with AB diblock copolymers only a few studies are available concerning the CDSA method for ABC terpolymers.

\section{Self-Assembly of AB and ABC Graft Copolymers in Organic Solvents}

Analogous to $\mathrm{AB}$ block copolymers, the $\mathrm{AB}$ graft copolymers may develop the basic sphere, cylinder, and vesicle micellar morphologies, as a function of molecular characteristics, selective solvent type, copolymer concentration, and self-aggregation process. Micellization of synthetic- and polysaccharide-based graft copolymers in aqueous media has been reviewed very recently by the present authors [23]. Therefore, it was necessary to complete this topic by providing an overview on the self-assembly of various types of graft copolymers in organic solvents. After recalling some basic graft copolymer characteristics, this section focus on AB graft copolymers, including the concept of unimolecular micelle formation, followed by the morphologies of $A B C$ graft structures.

As schematically shown in Figure 9, a graft copolymer is essentially defined by the $D P_{\mathrm{A}}$ and $D P_{\mathrm{B}}$ of the backbone and graft chain, respectively. A major molecular characteristic is further the graft density, which represents the number of side chains per 100 backbone monomer units. Moreover, assuming that the graft chains are randomly distributed along the backbone, the average distance $\Delta P$ between two grafting sites is thus accessible. 


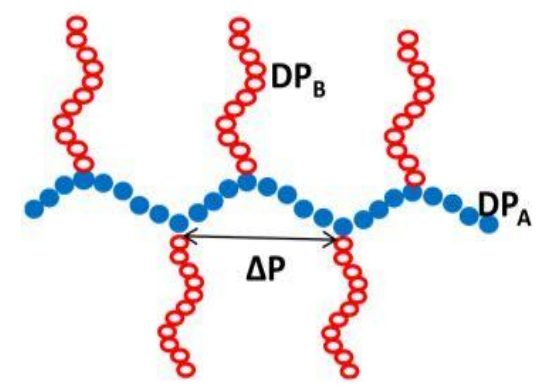

Figure 9. Schematically representation of an $\mathrm{AB}$ graft copolymer.

Already at the end of the last century, Kikuchi and Nose [106] clearly demonstrated that graft copolymers have a greater tendency than the corresponding block copolymers to form unimolecular micelles by intramolecular association of the backbone sequences. This tendency was well illustrated for PMMA-g-PS in organic solvents, such as iso-amyl acetate or in the presence of a mixture of acetonitrile and acetoacid ether. It appeared that the tendency of forming unimolecular micelles increases with an increasing graft density and molecular weight of the grafted chains. At high graft densities, unimolecular micelles are formed by intramolecular collapse of the backbone chain. In a theoretical approach, Borisov and Zhulina [107] admitted that the collapsing of the backbone chain occurs with formation of a "pearl neck-lace" stabilized by steric repulsion of the soluble side chains.

From the literature survey, as already mentioned, it turned out that the number of publications related to self-assembly of graft copolymers in aqueous media increased over the last two decades due to the predominant applications possibilities of these aqueous systems. Purely organic solvent-based systems have become rather scarce. In the following section, an overview of the recent investigations concerning the self-assembly of synthetic and natural-based graft copolymers in pure organic solvents, are reviewed.

\subsection{Self-Assembly of AB Graft Copolymers}

For the self-assembly studies of polysaccharide-based graft copolymers in organic solvents, a special mention could be made of the investigation of Liu et al. [108]. These authors reported the synthesis of ethyl cellulose-g-poly(acrylic acid) (EC-g-PAA), which leads to unimolecular micelles in DMF, methanol, and their mixtures with water by increasing the graft density. Francis et al. [109] described the synthesis of chitosan-g-PS and prepared micellar dispersions in DMF as these systems are of interest as metal complexing agents.

Analogous to the peptide/PtBMA water and organo-soluble composite investigations by Saha et al. [110], Bose et al. [111] reported peptide-based graft copolymers, such as tyrosine-g-polyoxazoline. The micellar structures of this type of copolymer were examined in aqueous and non-aqueous media. Concerning the recent example of a purely synthetic graft copolymer, Stepánek et al. [112] investigated the micellization in methanol and water of poly(4-methylstyrene)- $g$-poly(methacrylic acid) (P4MS-g-PMAA). In methanol, a tendency to form unimolecular micelles was demonstrated.

PtBMA-based graft copolymers, such as PS- $g$-PtBMA, were reported by Gromadzki et al. [113]. These authors examined the conformation of this type of copolymers in a non-selective solvent, such as a THF, as well as in n-amylalcohol, a selective solvent of the PtBMA graft chains. By increasing the graft density, a stretching of the PS backbone was noticed for the unimolecular micelles.

A typical example of fluorinated graft copolymers was studied by Koda et al. [114]. This type of thermo-sensitive copolymer leads to micelle formation in both fluorinated solvents and in water. As a final and recent example from this category of graft copolymers, mention has to be made of poly(phenyl carbodiimide)- $g$-poly(styrene) (PCD- $g$-PS) self-assembly in methanol described by Kurilov et al. [24]. The nano-ring morphologies obtained for this rod-coil copolymer were generated by 
surface-induced self-assembly in thin films, prepared by the controlled evaporation of THF/methanol copolymer solutions.

\subsection{Self-Assembly of ABC Graft Copolymers}

Various structures are available for $\mathrm{ABC}$ three-component graft copolymers and their micellization characteristics in aqueous media have been recently reviewed [23]. Concerning the micelle formation in organic media, a typical example that is related to the self-assembly of ABC graft copolymers, such as poly(1-dodecene-co-pMS)-g-PEO, was published by Liu et al. [115]. These authors performed an extensive study of their micellization behavior in $n$-octanol. As a function of the molecular weight of the PEG, 350, 750 and $2000 \mathrm{~g} \cdot \mathrm{mol}^{-1}$, respectively, the C.M.C increased from $1.28 \times 10^{-4}$ to $1.95 \times 10^{-4} \mathrm{~g} \cdot \mathrm{mL}^{-1}$. For the reversed spherical micelles, the size distributions were relatively large with typical diameters in the range of 71 to $186 \mathrm{~nm}$.

A detailed micellization study by small angle neutron scattering (SANS) was carried out by Alexander et al. [116] for PI-g-Pluronics. These authors investigated the micellization behavior of these graft copolymers in different solvents, such as THF, a common solvent for PI and Pluronics, and hexane and ethanol, which are selective solvents for PI and Pluronics, respectively. As expected, "flower-like" micelles were obtained in hexane, the selective solvent for the PI backbone chain, whereas "star-like" micelles were formed in ethanol. These morphologies are illustrated in Figure 10. This study was completed by the determination of the micellization onset as a function of the copolymer concentration in THF/hexane mixtures, ranging from pure THF to pure hexane.

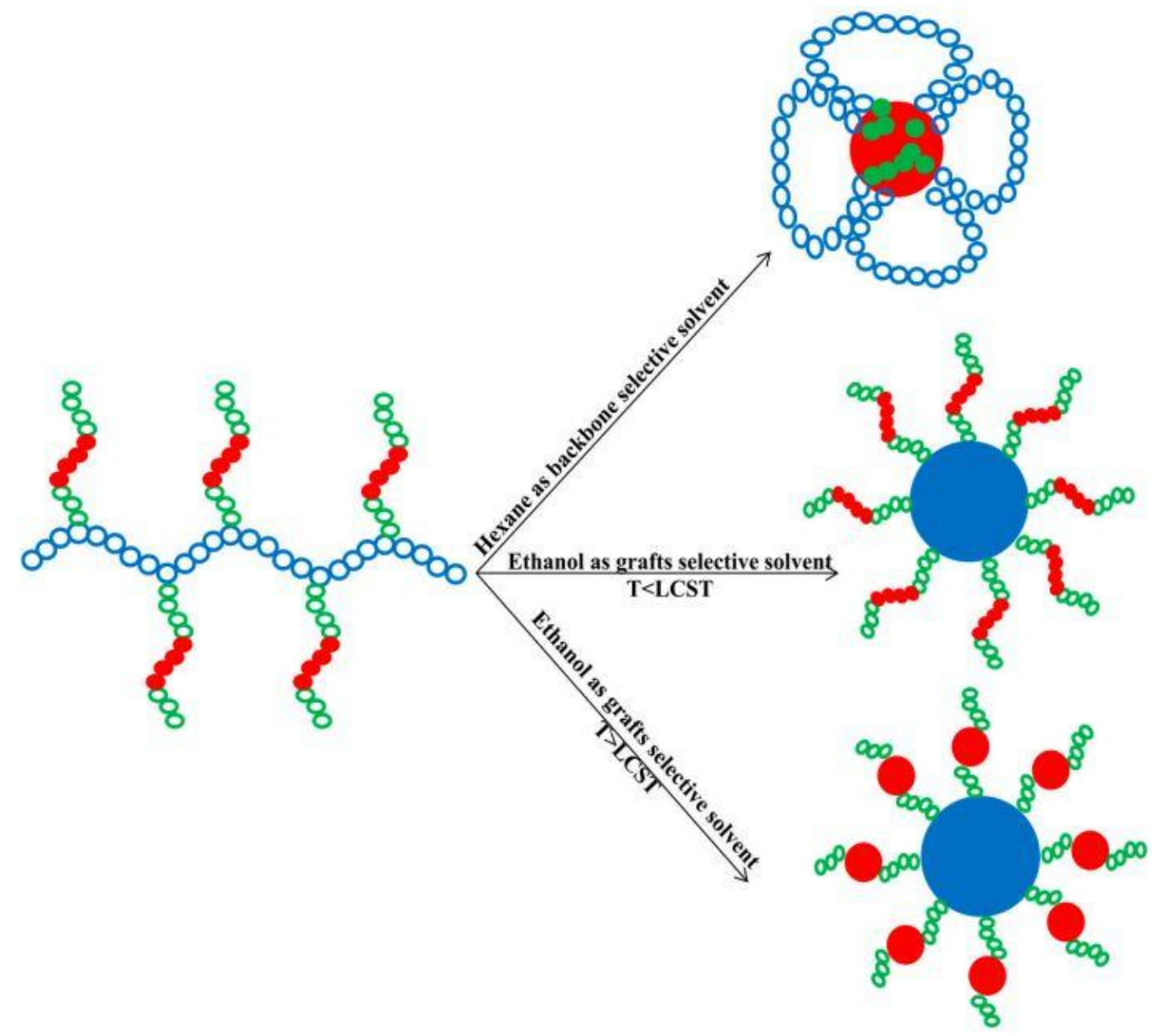

Figure 10. Micellar conformations of PI- $g$-Pluronic copolymers in hexane (backbone selective solvent) and in ethanol (grafts selective solvent). Adapted from Alexander et al. [116]. 
Mo et al. [117] extended the self-assembly concept to multigraft copolymers. Using the "click chemistry" preparation technique, they synthesized a series of PGMA-g-(PCEMA-PtBA-MPEG) having the same $\mathrm{P}\left(\mathrm{GMA}-\mathrm{N}_{3}\right)$ backbone, and three different type of side chains. In DMF, a common "good solvent" for both the backbone and side-chains, they observed by AFM a stretched "worm-like" conformation. With three different selective solvents $\left(\mathrm{CH}_{2} \mathrm{Cl}_{2}, \mathrm{CH}_{3} \mathrm{OH}\right.$, and $\left.\mathrm{H}_{2} \mathrm{O}\right)$, the morphologies of the unimolecular micelles varied from a "neck-lace" to "worm-like" and to multi-component spherical structures, as schematically illustrated in Figure 11.
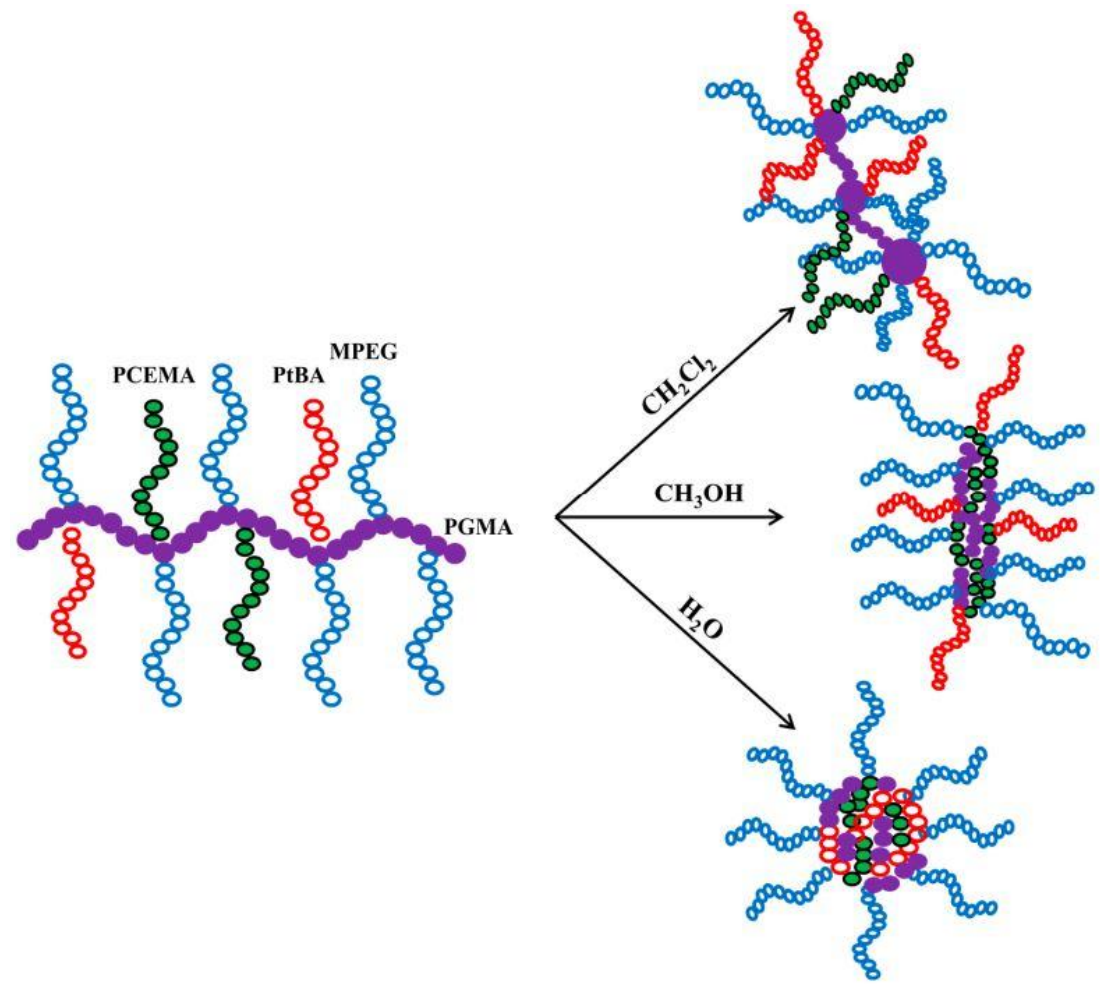

Figure 11. Micellar conformation of PGMA-g-(PCEMA-PtBA-MPEG) copolymers in $\mathrm{CH}_{2} \mathrm{Cl}_{2}, \mathrm{CH}_{3} \mathrm{OH}$ and $\mathrm{H}_{2} \mathrm{O}$ selective solvents, respectively. Adapted from Mo et al. [117].

\subsection{Concluding Remarks}

With the present synthesis methods, outlined in our recent review article [23], a wide range of $A B$ and $\mathrm{ABC}$ graft copolymers with various architectures are available in order to examine their behavior in organic solvents. In fact, over the last decade, this topic has attracted less research interest than self-assembly studies in aqueous media. With respect to block copolymers, graft copolymers have the advantage to form unimolecular micelles by adjusting the graft density. Moreover, they provide also access to natural-based products, such as polysaccharides comprising structures. By taking into account these specific features, original developments may be expected in this research area.

\section{General Conclusions and Perspectives}

The self-assembly of block and graft copolymers in aqueous media is undeniably at the present a major research trend given their biomedical application possibilities. Nevertheless, from our overview it turns out that micellar systems in non-aqueous solvents are of ongoing theoretical and practical interest.

For AB and ABA block copolymers, which are considered as "model molecular architectures", the recent studies were mainly focused on their self-assembly in polar and non-polar solvents, as well as in solvent mixtures. This last approach has the advantage that the micellar characteristics, such as size and morphology, can be triggered in a continuous way by adjusting the solvent mixture composition, 
and thus the "solvent quality". Over these last years, a major interest was further devoted to the micellization in ionic liquids as selective solvents. As this research area has reached its maturity, further developments may be expected for polyA- $b$-poly $(\mathrm{B}-c o-\mathrm{C})$ copolymers with a random or gradient $\mathrm{B}$ and $\mathrm{C}$ blocks. This approach is in fact an alternative to adjust the solubility parameter.

$A B C$ triblock terpolymers have developed into an extensive research area for the study of sophisticated micellar morphologies. Substantial advances were reported, in particular, for aqueous and non-aqueous systems, yielding multi-compartment micellar structures. For these multi-compartment nanoparticles, it was demonstrated that the sequence arrangement of the $A B C$ triblock terpolymers is a major structural parameter. Different morphologies are obtained in a given selective solvent for $\mathrm{ABC}, \mathrm{BAC}$, and $\mathrm{BCA}$ of the same composition and molecular weight. Even if the challenge remains for the polymer chemist, this concept should be estended to $A B C, B A C$, and $B C A$ copolymers to self-aggregation in organic solvents, including the biocompatible ILs.

Despite their wide-spread application possibilities, $\mathrm{AB}$ and $\mathrm{ABC}$ graft copolymers have attracted up-to-now relatively minor interest concerning the micellization in organic solvents. With respect to block copolymers, graft copolymers have the advantage that by adjusting the graft density brush-like structures, and unimolecular micelles can be obtained. Graft copolymers, based on natural polymeric precursors, may create opportunities for self-assemblies in organic solvents.

Finally, as well for block copolymers as for graft copolymers, an efficient control of the molecular architectures and the self-assembly parameters are still a major challenge for further investigations in this research area.

Author Contributions: Leonard Ionut Atanase and Gerard Riess conceived, designed and wrote this review.

Conflicts of Interest: The authors declare no conflict of interest.

\section{References}

1. Tuzar, Z.; Kratochvil, P. Block and graft copolymer micelles in solution. Adv. Colloid Interface Sci. 1976, 6, 201-232. [CrossRef]

2. Nakashima, K.; Bahadur, P. Aggregation of water-soluble block copolymers in aqueous solutions: Recent trends. Adv. Colloid Interface Sci. 2006, 123-126, 75-96. [CrossRef] [PubMed]

3. Cho, H.K.; Cheong, I.W.; Lee, J.M.; Kim, J.H. Polymeric nanoparticles, micelles and polymersomes from amphiphilic block copolymer. Korean J. Chem. Eng. 2010, 27, 731-740. [CrossRef]

4. Kulthe, S.S.; Choudhari, Y.M.; Inamdar, N.N.; Mourya, V. Polymeric micelles: Authoritative aspects for drug delivery. Des. Monomers Polym. 2012, 15, 465-521. [CrossRef]

5. Xu, W.; Ling, P.; Zhang, T. Polymeric micelles, a promising drug delivery system to enhance bioavailability of poorly water-soluble drugs. J. Drug Deliv. 2013. [CrossRef] [PubMed]

6. Ahmad, Z.; Shah, A.; Siddiq, M.; Kraatz, H.B. Polymeric micelles as drug delivery vehicles. RSC Adv. 2014, 4, 17028-17038. [CrossRef]

7. Riess, G. Micellization of block copolymers. Prog. Polym. Sci. 2003, 28, 1107-1170. [CrossRef]

8. Gohy, J.F. Block copolymer micelles. Adv. Polym. Sci. 2005, 190, 65-136. [CrossRef]

9. Mai, Y.; Eisenberg, A. Self-assembly of block copolymers. Chem. Soc. Rev. 2012, 41, 5969-5985. [CrossRef] [PubMed]

10. Bhattacharya, A.; Misra, B.N. Grafting: A versatile means to modify polymers. Techniques, factors and applications. Prog. Polym. Sci. 2004, 29, 767-814. [CrossRef]

11. Uhrig, D.; Mays, J. Synthesis of well-defined multigraft copolymers. Polym. Chem. 2011, 2, 69-76. [CrossRef]

12. Feng, C.; Li, Y.; Yang, D.; Hu, J.; Zhang, X.; Huang, X. Well-defined graft copolymers: From controlled synthesis to multipurpose applications. Chem. Soc. Rev. 2011, 40, 1282-1295. [CrossRef] [PubMed]

13. Deng, Y.; Zhang, S.; Lu, G.; Huang, X. Constructing well-defined star graft copolymers. Polym. Chem. 2013, 4, 1289-1299. [CrossRef]

14. Matsuo, Y.; Konno, R.; Ishizone, T.; Goseki, R.; Hirao, A. Precise synthesis of block polymers composed of three or more blocks by specially designed linking methodologies in conjunction with living anionic polymerization system. Polymers 2013, 5, 1012-1040. [CrossRef] 
15. Keddie, D.J. A guide to the synthesis of block copolymers using reversible-addition fragmentation chain transfer (RAFT) polymerization. Chem. Soc. Rev. 2014, 43, 496-505. [CrossRef] [PubMed]

16. Jennings, J.; He, G.; Howdle, S.M.; Zetterlund, P.B. Block copolymer synthesis by controlled/living radical polymerization in heterogeneous systems. Chem. Soc. Rev. 2016, 45, 5055-5084. [CrossRef] [PubMed]

17. Lopez-Oliva, A.P.; Warren, N.J.; Rajkumar, A.; Mykhaylyk, O.O.; Derry, M.J.; Doncom, K.E.B.; Rymaruk, M.J.; Armes, S.P. Polydimethylsiloxane-based diblock copolymer nano-objects prepared in nonpolar media via RAFT-mediated polymerization-induced self-assembly. Macromolecules 2015, 48, 3547-3555. [CrossRef]

18. Jones, E.R.; Semsarilar, M.; Wyman, P.; Boerakker, M.; Armes, S.P. Addition of water to an alcoholic RAFT PISA formulation leads to faster kinetics but limits the evolution of copolymer morphology. Polym. Chem. 2016, 7, 851-859. [CrossRef]

19. Ratcliffe, L.P.D.; McKenzie, B.E.; Le Bouedec, G.M.D.; Williams, C.N.; Brown, S.L.; Armes, S.P. Polymerization-induced self-assembly of all-acrylic diblock copolymers via RAFT dispersion polymerization in alkanes. Macromolecules 2015, 48, 8594-8607. [CrossRef]

20. Canning, S.L.; Smith, G.N.; Armes, S.P. A critical appraisal of RAFT-mediated polymerization-induced self-assembly. Macromolecules 2016, 49, 1985-2001. [CrossRef] [PubMed]

21. Canning, S.L.; Cunningham, V.J.; Ratcliffe, L.P.D.; Armes, S.P. Phenyl acrylate is a versatile monomer for the synthesis of acrylic diblock copolymer nano-objects via polymerization-induced self-assembly. Polym. Chem. 2017, 8, 4811-4821. [CrossRef]

22. Van Krevelen, D.W. Properties of Polymers, 3rd ed.; Elsevier Sci.: Amsterdam, The Netherlands, 2003; pp. 189-224. ISBN 044482877X.

23. Atanase, L.I.; Desbrieres, J.; Riess, R. Micellization of synthetic and polysaccharides-based graft copolymers in aqueous media. Prog. Polym. Sci. 2017, 73, 32-60. [CrossRef]

24. Kulikov, O.V.; Siriwardane, D.A.; McCandless, G.T.; Mahmood, S.F.; Novak, B.M. Self-assembly studies on triazolepolycarbodiimide-g-polystyrene copolymers. Polymer 2016, 92, 94-101. [CrossRef]

25. Hudson, Z.M.; Boott, C.E.; Robinson, M.E.; Rupar, P.A.; Winnik, M.A.; Manners, I. Tailored hierarchical micelle architectures using living crystallization-driven self-assembly in two dimensions. Nat. Chem. 2014, 6, 893-898. [CrossRef] [PubMed]

26. Hailes, R.L.N.; Oliver, A.M.; Gwyther, J.; Whittell, G.R.; Manners, I. Polyferrocenylsilanes: Synthesis, properties and applications. Chem. Soc. Rev. 2016, 45, 5358-5407. [CrossRef] [PubMed]

27. Tritschler, U.; Pearce, S.; Gwyther, J.; Whittell, G.R.; Manners, I. Functional nanoparticles from the solution self-assembly of block copolymers. Macromolecules 2017, 50, 3439-3463. [CrossRef]

28. Winnik, F.M.; Regismond, S.T.A.; Anghel, D.F. Fluorescent labels: Versatile tools for studying the association of amphiphilic polymers in water. In Associative Polymers in Aqueous Media; Glass, J.E., Ed.; American Chemical Society: Washington, DC, USA, 2010; Volume 17, pp. 286-302. ISBN 9780841236592.

29. Štěpánek, M. Fluorescence spectroscopy studies of amphiphilic block copolymer micelles in aqueous solutions. In Fluoresce Studies of Polymer Containing Systems; Procházka, K., Ed.; Springer: Cham, Switzerland, 2016; Volume 16, pp. 203-215. ISBN 978-3-319-26786-9.

30. Walker, L.M. Scattering from polymer-like micelles. Curr. Opin. Colloid Interface Sci. 2009, 14, 451-454. [CrossRef]

31. Chavda, S.; Yusa, S.; Inoue, M.; Abezgauz, L.; Kesselman, E.; Danino, D.; Bahadur, P. Synthesis of stimuli responsive $\mathrm{PEG}_{47}-b$-PAA $126-b$-PSt 32 triblock copolymer and its self-assembly in aqueous solutions. Eur. Polym. J. 2013, 49, 209-216. [CrossRef]

32. Löbling, T.I.; Haataja, J.S.; Synatschke, C.V.; Schacher, F.H.; Müller, M.; Hanisch, A.; Gröschel, A.H.; Müller, A.H.E. Hidden structural features of multicompartment micelles revealed by cryogenic transmission electron tomography. ACS Nano 2014, 8, 11330-11340. [CrossRef] [PubMed]

33. Franken, L.E.; Boekema, E.J.; Stuart, M.C.A. Transmission electron microscopy as a tool for the characterization of soft materials: Application and interpretation. Adv. Sci. 2017, 4, 1600476. [CrossRef] [PubMed]

34. Boott, C.E.; Laine, R.F.; Mahou, P.; Finnegan, J.R.; Leitao, E.M.; Webb, S.E.D.; Kaminski, C.F.; Manners, I. In situ visualization of block copolymer self-assembly in organic media by super-resolution fluorescence microscopy. Chem. Eur. J. 2015, 21, 18539-18542. [CrossRef] [PubMed] 
35. Li, S.; Huo, F.; Li, Q.; Gao, C.; Su, Y.; Zhang, W. Synthesis of a doubly thermo-responsive schizophrenic diblock copolymer based on poly[ $N$-(4-vinylbenzyl)- $N, N$-diethylamine] and its temperature-sensitive flip-flop micellization. Polym. Chem. 2014, 5, 3910-3918. [CrossRef]

36. Sotiriou, K.; Nannou, A.; Velis, G.; Pispas, S. Micellization behavior of PS(PI) 3 miktoarm star copolymers. Macromolecules 2002, 35, 4106-4112. [CrossRef]

37. Sotiriou, K.; Pispas, S.; Hadjichristidis, N. Controlling the colloidal behavior of styrene-isoprene diblock copolymers by selective end functionalization. Colloids Surf. Part A Physicochem. Eng. Asp. 2007, 293, 51-57. [CrossRef]

38. Di Cola, E.; Lefebvre, C.; Deffieux, A.; Narayanan, T.; Borsali, R. Micellar transformations of poly(styrene-b-isoprene) block copolymers in selective solvents. Soft Matter 2009, 5, 1081-1090. [CrossRef]

39. Lund, R.; Willner, L.; Lindner, P.; Richter, D. Structural properties of weakly segregated PS-PB block copolymer micelles in $n$-alkanes: Solvent entropy effects. Macromolecules 2009, 42, 2686-2695. [CrossRef]

40. Cheng, G.; Hammouda, B.; Perahia, D. Polystyrene-block-polyisoprene diblock-copolymer micelles: Coupled pressure and temperature effects. Macromol. Chem. Phys. 2014, 215, 776-782. [CrossRef]

41. Growney, D.J.; Mykhaylyk, O.O.; Armes, S.P. Micellization and adsorption behavior of a near-monodisperse polystyrene-based diblock copolymer in nonpolar media. Langmuir 2014, 30, 6047-6056. [CrossRef] [PubMed]

42. Bartels, J.W.; Cauet, S.I.; Billings, P.L.; Lin, L.Y.; Zhu, J.; Fidge, C.; Pochan, D.J.; Wooley, K.L. Evaluation of isoprene chain extension from PEO macromolecular chain transfer agents for the preparation of dual, invertible block copolymer nanoassemblies. Macromolecules 2010, 43, 7128-7138. [CrossRef] [PubMed]

43. Wang, X.; Davis, J.L.; Hinestrosa, J.P.; Mays, J.W.; Kilbey, S.M. Control of self-assembled structure through architecturally and compositionally complex block copolymer surfactant mixtures. Macromolecules 2014, 47, 7138-7150. [CrossRef]

44. Arai, T.; Masaoka, M.; Michitaka, T.; Watanabe, Y.; Hashidzume, A.; Sato, T. Aggregation behavior of polystyrene-based amphiphilic copolymers in organic media. Polym. J. 2014, 46, 189-194. [CrossRef]

45. Hussain, H.; Tan, B.H.; Gudipati, C.S.; He, C.B.; Liu, Y.; Davis, T.P. Micelle formation of amphiphilic polystyrene- $b$-poly( $N$-vinylpyrrolidone) diblock copolymer in methanol and water-methanol binary mixtures. Langmuir 2009, 25, 5557-5564. [CrossRef] [PubMed]

46. Shao, Y.; Aizhao, P.; Ling, He. POSS end-capped diblock copolymers: Synthesis, micelle self-assembly and properties. J. Colloid Interface Sci. 2014, 425, 5-11. [CrossRef] [PubMed]

47. Liaw, C.Y.; Henderson, K.J.; Burghardt, W.R.; Wang, J.; Shull, K.R. Micellar morphologies of block copolymer solutions near the sphere/cylinder transition. Macromolecules 2015, 48, 173-183. [CrossRef]

48. Jena, S.S.; Roy, S.G.; Azmeera, V.; De, P. Solvent-dependent self-assembly behavior of block copolymers having side-chain amino acid and fatty acid block segments. React. Funct. Polym. 2016, 99, 26-34. [CrossRef]

49. Jana, S.; Saha, A.; Paira, T.K.; Mandal, T.K. Synthesis and self-aggregation of poly(2-ethyl-2-oxazoline)-based photo-cleavable block copolymer: Micelle, compound micelle, reverse micelle, and dye encapsulation/release. J. Phys. Chem. B 2016, 120, 813-824. [CrossRef] [PubMed]

50. Demarteau, J.; Ameduri, B.; Ladmiral, V.; Mees, M.A.; Hoogenboom, R.; Debuigne, A.; Detrembleur, C. Controlled synthesis of fluorinated copolymers via cobalt-mediated radical copolymerization of perfluorohexylethylene and vinyl acetate. Macromolecules 2017, 50, 3750-3760. [CrossRef]

51. Pospiech, D.; Jehnichen, D.; Eckstein, K.; Scheibe, P.; Komber, H.; Sahre, K.; Janke, A.; Reuter, U.; Häußler, L.; Schellkopf, L.; et al. Semifluorinated PMMA block copolymers: Synthesis, nanostructure, and thin film properties. Macromol. Chem. Phys. 2017, 218, 1600599. [CrossRef]

52. Cho, H.; Park, H.; Park, S.; Choi, H.; Huang, H.; Chang, T. Development of various PS-b-P4VP micellar morphologies: Fabrication of inorganic nanostructures from micellar templates. J. Colloid Interface Sci. 2011, 356, 1-7. [CrossRef] [PubMed]

53. Zhou, Y.N.; Cheng, H.; Luo, Z.H. Fluorinated AB diblock copolymers and their aggregates in organic solvents. J. Polym. Sci. Part A Polym. Chem. 2011, 49, 3647-3657. [CrossRef]

54. Wang, L.; Yu, X.; Yang, S.; Zheng, J.X.; Van Horn, R.M.; Zhang, W.B.; Xu, J.; Cheng, S.Z.D. Polystyrene-block-poly(ethylene oxide) reverse micelles and their temperature-driven morphological transitions in organic solvents. Macromolecules 2012, 45, 3634-3638. [CrossRef]

55. Rao, J.; Zhang, H.; Gaan, S.; Salentinig, S. Self-assembly of polystyrene-b-poly(2-vinylpyridine) micelles: From solutions to silica particles surfaces. Macromolecules 2016, 49, 5978-5984. [CrossRef] 
56. Choi, S.H.; Lee, W.B.; Lodge, T.P.; Bates, F.S. Structure of poly(styrene- $b$-ethylene-alt-propylene) diblock copolymer micelles in binary solvent mixtures. J. Polym. Sci. Part A Polym. Phys. 2016, 54, 22-31. [CrossRef]

57. Derry, M.J.; Fielding, L.A.; Armes, S.P. Polymerization-induced self-assembly of block copolymer nanoparticles via RAFT non-aqueous dispersion polymerization. Prog. Polym. Sci. 2016, 52, 1-18. [CrossRef]

58. Lee, H.N.; Bai, Z.; Newell, N.; Lodge, T.P. Micelle/inverse micelle self-assembly of a PEO-PNIPAm block copolymer in ionic liquids with double thermoresponsivity. Macromolecules 2010, 43, 9522-9528. [CrossRef]

59. Lu, H.; Akgun, B.; Wei, X.; Li, L.; Satija, S.K.; Russel, T.P. Temperature-triggered micellization of block copolymers on an ionic liquid surface. Langmuir 2011, 27, 12443-12450. [CrossRef] [PubMed]

60. Ueki, T.; Nakamura, Y.; Lodge, T.P.; Watanabe, M. Light-controlled reversible micellization of a diblock copolymer in an ionic liquid. Macromolecules 2012, 45, 7566-7573. [CrossRef]

61. Hoarfrost, M.L.; Lodge, T.P. Effects of solvent quality and degree of polymerization on the critical micelle temperature of poly(ethylene oxide- $b$ - $n$-butyl methacrylate) in ionic liquids. Macromolecules 2014, 47, 1455-1461. [CrossRef]

62. Chen, Z.; FitzGerald, P.A.; Kobayashi, Y.; Ueno, K.; Watanabe, M.; Warr, G.G.; Atkin, R. Micelle structure of novel diblock polyethers in water and two protic ionic liquids (EAN and PAN). Macromolecules 2015, 48, 1843-1851. [CrossRef]

63. Kobayashi, Y.; Kitazawa, Y.; Komori, T.; Ueno, K.; Kokubo, H.; Watanabe, M. Self-assembly of polyether diblock copolymers in water and ionic liquids. Macromol. Rapid Commun. 2016, 37, 1207-1211. [CrossRef] [PubMed]

64. Ma, Y.; Lodge, T.P. Chain exchange kinetics in diblock copolymer micelles in ionic liquids: The role of $\chi$. Macromolecules 2016, 49, 9542-9552. [CrossRef]

65. Ma, Y.; Lodge, T.P. Poly(methyl methacrylate)-block-poly( $n$-butyl methacrylate) diblock copolymer micelles in an ionic liquid: Scalling of core and corona size with core block length. Macromolecules 2016, 49, 3639-3646. [CrossRef]

66. Simone, P.M.; Lodge, T.P. Micellization of PS-PMMA diblock copolymers in an ionic liquid. Macromol. Chem. Phys. 2007, 208, 339-348. [CrossRef]

67. Mok, M.M.; Thiagarajan, R.; Flores, M.; Morse, D.C.; Lodge, T.P. Apparent critical micelle concentrations in block copolymer/ionic liquid solutions: Remarkably weak dependence on solvophobic block molecular weight. Macromolecules 2012, 45, 4818-4829. [CrossRef]

68. He, Y.; Li, Z.; Simone, P.; Lodge, T.P. Self-assembly of block copolymer micelles in an ionic liquid. J. Am. Chem. Soc. 2006, 128, 2745-2750. [CrossRef] [PubMed]

69. Meli, L.; Santiago, J.M.; Lodge, T.P. Path-dependent morphology and relaxation kinetics of highly amphiphilic diblock copolymer micelles in ionic liquids. Macromolecules 2010, 43, 2018-2027. [CrossRef]

70. Zhang, S.; Li, N.; Zheng, L.; Li, X.; Gao, Y.; Yu, L. Aggregation behavior of pluronic triblock copolymer in 1-butyl-3-methylimidazolium type ionic liquids. J. Phys. Chem. B 2008, 112, 10228-10233. [CrossRef] [PubMed]

71. Lopez-Barron, C.R.; Li, D.; Wagner, N.J.; Caplan, J.L. Triblock copolymer self-assembly in ionic liquids: Effect of PEO block length on the self-assembly of PEO-PPO-PEO in ethylammonium nitrate. Macromolecules 2014, 47, 7484-7495. [CrossRef]

72. Miller, A.C.; Bershteyn, A.; Tan, W.; Hammond, P.T.; Cohen, R.E.; Irvine, D.J. Block copolymer micelles as nanocontainers for controlled release of proteins from biocompatible oil phases. Biomacromolecules 2009, 10, 732-741. [CrossRef] [PubMed]

73. Atanase, L.I.; Riess, G. Block copolymer stabilized nonaqueous biocompatible sub-micron emulsions for topical applications. Int. J. Pharm. 2013, 448, 339-345. [CrossRef] [PubMed]

74. Atanase, L.I.; Riess, G. Stabilization of non-aqueous emulsions by poly(2-vinylpyridine)-b-poly(butadiene) block copolymers. Colloids Surf. Part A Physicochem. Eng. Asp. 2014, 458, 19-24. [CrossRef]

75. Atanase, L.I.; Riess, G. PEG 400/Paraffin oil non-aqueous emulsions stabilized by PBut-block-P2VP block copolymers. J. Appl. Polym. Sci. 2015, 132, 41390-41397. [CrossRef]

76. He, W.N.; Xu, J.T. Crystallization assisted self-assembly of semicrystalline block copolymers. Prog. Polym. Sci. 2012, 37, 1350-1400. [CrossRef]

77. Crassous, J.J.; Schurtenberger, P.; Ballauff, M.; Mihut, A.M. Design of block copolymer micelles via crystallization. Polymer 2015, 62, 1-13. [CrossRef] 
78. Mihut, A.M.; Crassous, J.J.; Schmalz, H.; Ballauf, M. Crystallization-induced aggregation of block copolymer micelles: Influence of crystallization kinetics on morphology. Colloid Polym. Sci. 2010, 288, 573-578. [CrossRef]

79. Wang, H.; Wu, C.; Xia, G.; Ma, Z.; Mo, G.; Song, R. Semi-crystalline polymethylene-b-poly(acrylic acid) diblock copolymers: Aggregation behavior, confined crystallization and controlled growth of semycrystalline micelles from dilute DMF solution. Soft Matter 2015, 11, 1778-1787. [CrossRef] [PubMed]

80. Wang, T.; Zhang, X.; Li, X.; Gao, X.; Song, L. Crystallization and morphology transition of P2VP-b-PEO block copolymer micelles composed of an amorphous core and a crystallizable corona. Polym. Bull. 2015, 73, 773-789. [CrossRef]

81. Zhou, H.; Lu, Y.; Zhang, M.; Guerin, G.; Manners, I.; Winnik, M.A. PFS-b-PNIPAM: A first step toward polymeric nanofibrillar hydrogels based on uniform fiber-like micelles. Macromolecules 2016, 49, 4265-4276. [CrossRef]

82. Groves, P. Diffusion ordered spectroscopy (DOSY) as applied to polymers. Polym. Chem. 2017, 8, 6700-6708. [CrossRef]

83. Wyman, I.W.; Liu, G. Micellar structures of linear triblock terpolymers: Three blocks but many possibilities. Polymer 2013, 54, 1950-1978. [CrossRef]

84. Gröschel, A.H.; Müller, A.H.E. Sell-assembly concepts for multicompartment nanostructures. Nanoscale 2015, 7, 11841-11876. [CrossRef] [PubMed]

85. Marsat, J.N.; Heydenreich, M.; Kleinpeter, E.; Berlepsch, H.; Böttcher, C.; Laschewsky, A. Self-assembly into multicompartment micelles and selective solubilization by hydrophilic-lipophilic-flurophilic block copolymers. Macromolecules 2011, 44, 2092-2105. [CrossRef]

86. Kyeremateng, S.O.; Busse, K.; Kohlbrecher, J.; Kressler, J. Synthesis and self-organization of poly(propylene oxide)-based amphiphilic and triphilic block copolymers. Macromolecules 2011, 44, 583-593. [CrossRef]

87. Zhang, Y.; Lin, W.; Jing, R.; Huang, J. Effect of block sequence on the self-assembly of ABC terpolymers in selective solvent. J. Phys. Chem. B 2008, 112, 16455-16460. [CrossRef] [PubMed]

88. Lerch, J.P.; Atanase, L.I.; Purcar, V.; Riess, G. Self-aggregation of poly(butadiene)- $b$-poly(2-vinylpyridine0- $b$-poly(ethylene oxide) triblock copolymers in heptanes studied by viscometry and dynamic light scattering. C. R. Chim. 2017, 20, 724-729. [CrossRef]

89. Lerch, J.P.; Atanase, L.I.; Riess, G. Adsorption of non-ionic ABC triblock copolymers: Surface modification of $\mathrm{TiO}_{2}$ suspensions in aqueous and non-aqueous medium. Appl. Surf. Sci. 2017, 419, 713-719. [CrossRef]

90. Noolandi, J.; Hong, K.M. Theory of block copolymer micelles in solution. Macromolecules 1983, 16, $1443-1448$. [CrossRef]

91. Tsitsilianis, C.; Sfika, V. Heteroarm star-like micelles formed from polystyrene-block-poly(2-vinyl pyridine)-block-poly(methyl methacrylate) ABC triblock copolymers in toluene. Macromol. Rapid Commun. 2001, 22, 647-651. [CrossRef]

92. Bütün, V.; Taktak, F.F.; Tuncer, C. Tertiary amine methacrylate-based ABC triblock copolymers: Synthesis, characterization, and self-assembly in both aqueous and nonaqueous media. Macromol. Chem. Phys. 2011, 212, 1115-1128. [CrossRef]

93. Njikang, G.; Han, D.; Wang, J.; Liu, G. ABC triblock micelle-like aggregates in selective solvents for A and C. Macromolecules 2008, 41, 9727-9735. [CrossRef]

94. Schacher, F.; Walther, A.; Ruppel, M.; Drechsler, M.; Müller, A.H.E. Multicompartment core micelles of triblock terpolymers in organic media. Macromolecules 2009, 42, 3540-3548. [CrossRef]

95. Dupont, J.; Liu, G. ABC triblock copolymer hamburger-like micelles, segmented cylinders, and Janus particles. Soft Matter 2010, 6, 3654-3661. [CrossRef]

96. Muslim, A.; Shi, Y.; Yan, Y.; Yao, D.; Rexit, A.A. Preparation of cylindrical multi-compartment micelles by the hierarchical self-assembly of ABC triblock polymer in solution. RSC Adv. 2015, 5, 85446-85452. [CrossRef]

97. Löbling, T.I.; Ikkala, O.; Gröschel, A.H.; Müller, A.H.E. Controlling multicompartment morphologies using solvent conditions and chemical modification. ACS Macro Lett. 2016, 5, 1044-1048. [CrossRef]

98. Cong, Y.; Zhou, Q.; Fang, J.; Zhu, K. Morphology transformation of multicompartment self-assemblies of ABC triblock copolymers. Polymer 2017, 116, 173-177. [CrossRef]

99. Wang, L.; Huang, H.; He, T. ABC triblock terpolymer self-assembled core-shel-corona nanotubes with high aspect ratios. Macromol. Rapid. Commun. 2014, 35, 1387-1396. [CrossRef] [PubMed] 
100. Löbling, T.I.; Borisov, O.; Haataja, J.S.; Ikkala, O.; Gröschel, A.H.; Müller, A.H.E. Rational design of ABC triblock terpolymer solution nanostructures with controlled patch morphology. Nat. Commun. 2016, 7, 12097. [CrossRef] [PubMed]

101. Kitazawa, Y.; Ueki, T.; McIntosh, L.D.; Tamura, S.; Niitsuma, K.; Imaizumi, S.; Lodge, T.P.; Watanabe, M. Hierarchical sol-gel transition induced by thermosensitive self-assembly of an ABC triblock polymer in an ionic liquid. Macromolecules 2016, 49, 1414-1423. [CrossRef]

102. Wang, X.S.; Winnik, M.A.; Manners, I. Synthesis and solution self-assembly of coil-crystalline-coil polyferrocenylphosphine- $b$-polyferrocenylsilane-b-polysiloxane triblock copolymers. Macromolecules 2002, 35, 9146-9150. [CrossRef]

103. Schmelz, J.; Karg, M.; Hellweg, T.; Schmalz, H. General pathway toward crystalline-core micelles with tunable morphology and corona segregation. ACS Nano 2011, 5, 9523-9534. [CrossRef] [PubMed]

104. Atanase, L.I.; Lerch, J.P.; Riess, G. Water dispersibility of non-aqueous emulsions stabilized and viscosified by a poly(butadiene)-poly(2-vinylpyridine)-poly(ethylene oxide) (PBut-P2VP-PEO) triblock copolymer. Colloids Surf. Part A Physicochem. Eng. Asp. 2015, 464, 89-95. [CrossRef]

105. Betthausen, E.; Hanske, C.; Müller, M.; Fery, A.; Schacher, F.H.; Müller, A.H.E.; Pochan, D.J. Self-assembly of amphiphilic triblock terpolymers mediated by multifunctional organic acids: Vesicles, toroids, and (undulated) ribbons. Macromolecules 2014, 47, 1672-1683. [CrossRef]

106. Kikuchi, A.; Nose, T. Unimolecular micelle formation of poly(methyl methacrylate)-graft-polystyrene in mixed selective solvents of acetonitrile/acetoacetic acid ethyl ether. Macromolecules 1996, 29, 6770-6777. [CrossRef]

107. Borisov, O.V.; Zhulina, E.B. Amphiphilic graft copolymer in a selective solvent: Intramolecular structures and conformational transitions. Macromolecules 2005, 38, 2506-2514. [CrossRef]

108. Liu, W.; Liu, Y.; Hao, X.; Zeng, G.; Wang, W.; Liu, R.; Huang, Y. Backbone-collapsed intra- and inter-molecular self-assembly of cellulose-based dense graft copolymer. Carbohydr. Polym. 2012, 88, 290-298. [CrossRef]

109. Francis, R.; Baby, D.K.; Gnanou, Y. Synthesis and self-assembly of chitosan-g-polystyrene copolymer: A new route for the preparation of heavy metal nanoparticles. J. Colloid Interface Sci. 2015, 438, 110-115. [CrossRef] [PubMed]

110. Saha, A.; Jana, S.; Mandal, T.K. Peptide-poly(tert-butyl methacrylate) conjugate into composite micelles in organic solvents versus peptide-poly(methacrylic acid) conjugate into spherical and worm-like micelles in water: Synthesis and self-assembly. J. Polym. Sci. Part A Polym Chem. 2016, 54, 3019-3031. [CrossRef]

111. Bose, A.; Jana, S.; Saha, A.; Mandal, T.K. Amphiphilic polypeptide-polyoxazoline graft copolymer conjugate with tunable thermoresponsiveness: Synthesis and self-assembly into various micellar structures in aqueous and nonaqueous media. Polymer 2017, 110, 12-24. [CrossRef]

112. Stepánek, M.; Kosovan, P.; Procházka, K. Self-assembly of poly(4-methylstyrene)-g-poly(methacrylic acid) graft copolymer in selective solvents for grafts: Scattering and molecular dynamics simulation study. Langmuir 2010, 26, 9289-9296. [CrossRef] [PubMed]

113. Gromadzki, D.; Filippov, S.; Netopilik, M.; Makuska, R.; Jigounov, A.; Plestil, J.; Horsky, J.; Stepánek, P. Combination of "living" nitroxide-mediated and photoiniferter-induced "grafting from" free-radical polymerizations: From branched copolymers to unimolecular micelles and microgels. Eur. Polym. J. 2009, 45, 1748-1758. [CrossRef]

114. Koda, Y.; Terachima, T.; Sawamoto, M. Multimode self-folding polymers via reversible and thermoresponsive self-assembly of amphiphilic/fluorous random copolymers. Macromolecules 2016, 49, 4534-4543. [CrossRef]

115. Liu, M.; Fu, Z.; Wang, Q.; Xu, J.; Fan, Z. Study of amphiphilic poly(1-dodecene-co-para-methylstyrene)-graft-poly(ethylene glycol). Part II: Preparation and micellization behavior of the amphiphilic copolymers. Eur. Polym. J. 2008, 44, 4122-4128. [CrossRef] 
116. Alexander, S.; Cosgrove, T.; de Vos, W.M.; Castle, T.C.; Prescott, S.W. Aggregation behavior of polyisoprene-pluronic graft copolymers in selective solvents. Langmuir 2014, 30, 5747-5754. [CrossRef] [PubMed]

117. Mo, Y.; Liu, G.; Tu, Y.; Lin, S.; Song, J.; Hu, J.; Liu, F. Morphological switching of unimolar micelles of ternary graft copolymers in different solvents. J. Polym. Sci. Part A Polym. Chem. 2017, 55, 1021-1030. [CrossRef] 